Supporting Information

\title{
Metal-Free Catalyzed Synthesis of Fluorescent Indolizine Derivatives
}

Yu-Chang Yuan, Tian-Zhen Liu, Bao-Xiang Zhao *

*Institute of Organic Chemistry, School of Chemistry and Chemical Engineering, Shandong University, Jinan 250100, PR China

E-mail addresses: bxzhao@sdu.edu.cn.

\section{Table of contents}

1. ${ }^{1} \mathrm{H}$ NMR, ${ }^{13} \mathrm{C}\left\{{ }^{1} \mathrm{H}\right\}$ NMR, IR spectra and HRMS spectra of compounds ........................... S2

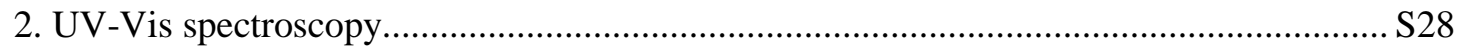

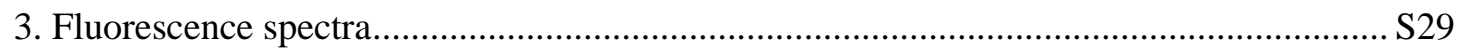

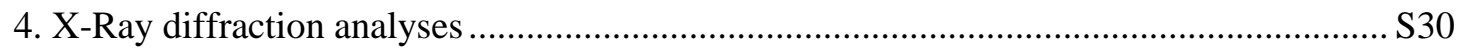




\section{1. ${ }^{1} \mathrm{H}$ NMR, ${ }^{13} \mathrm{C}\left\{{ }^{1} \mathrm{H}\right\}$ NMR, IR spectra and HRMS spectra of compounds}

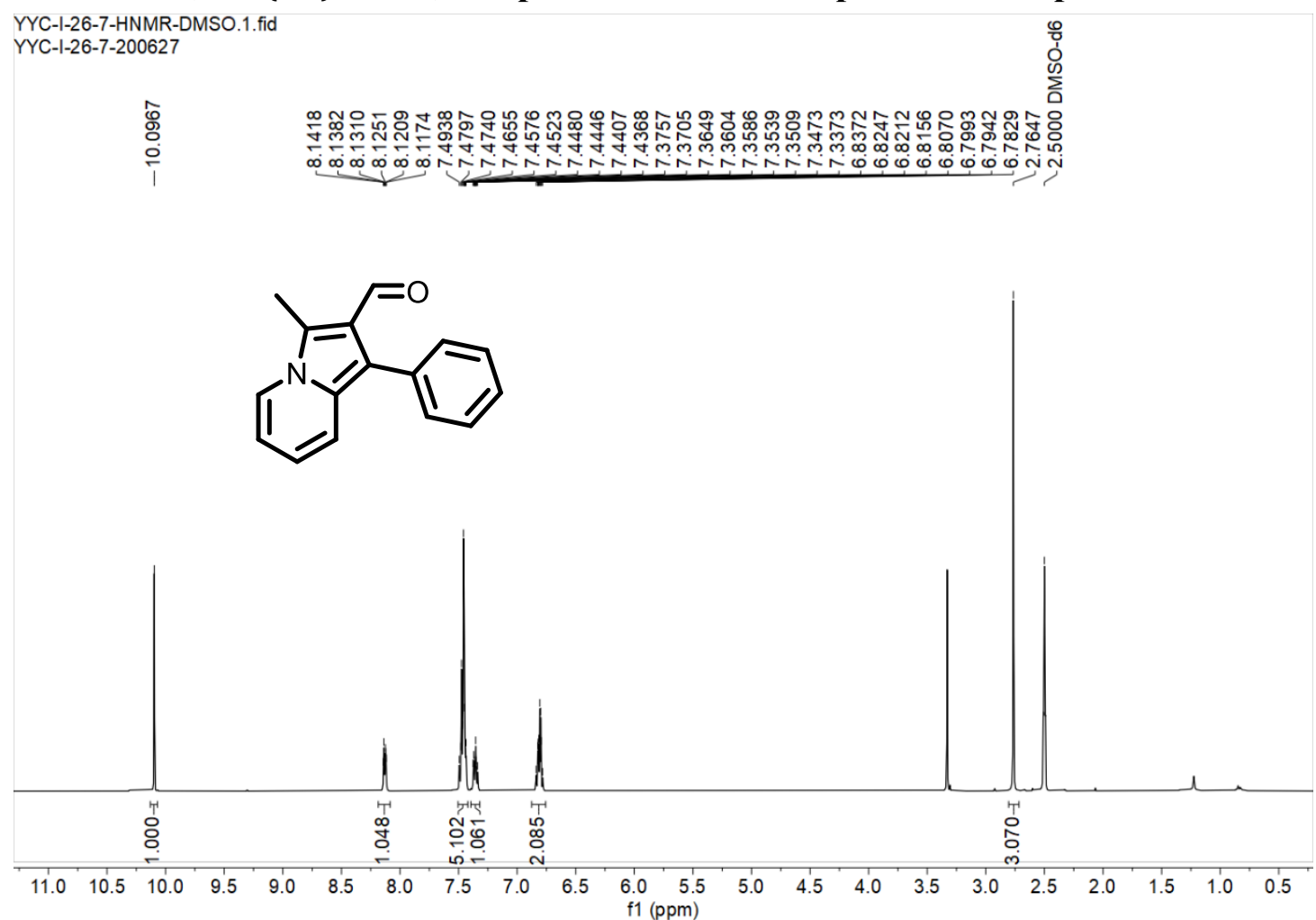

Figure $\mathrm{S} 1{ }^{1} \mathrm{H}$ NMR (400 MHz, DMSO- $d_{6}$ ) of compound 3a

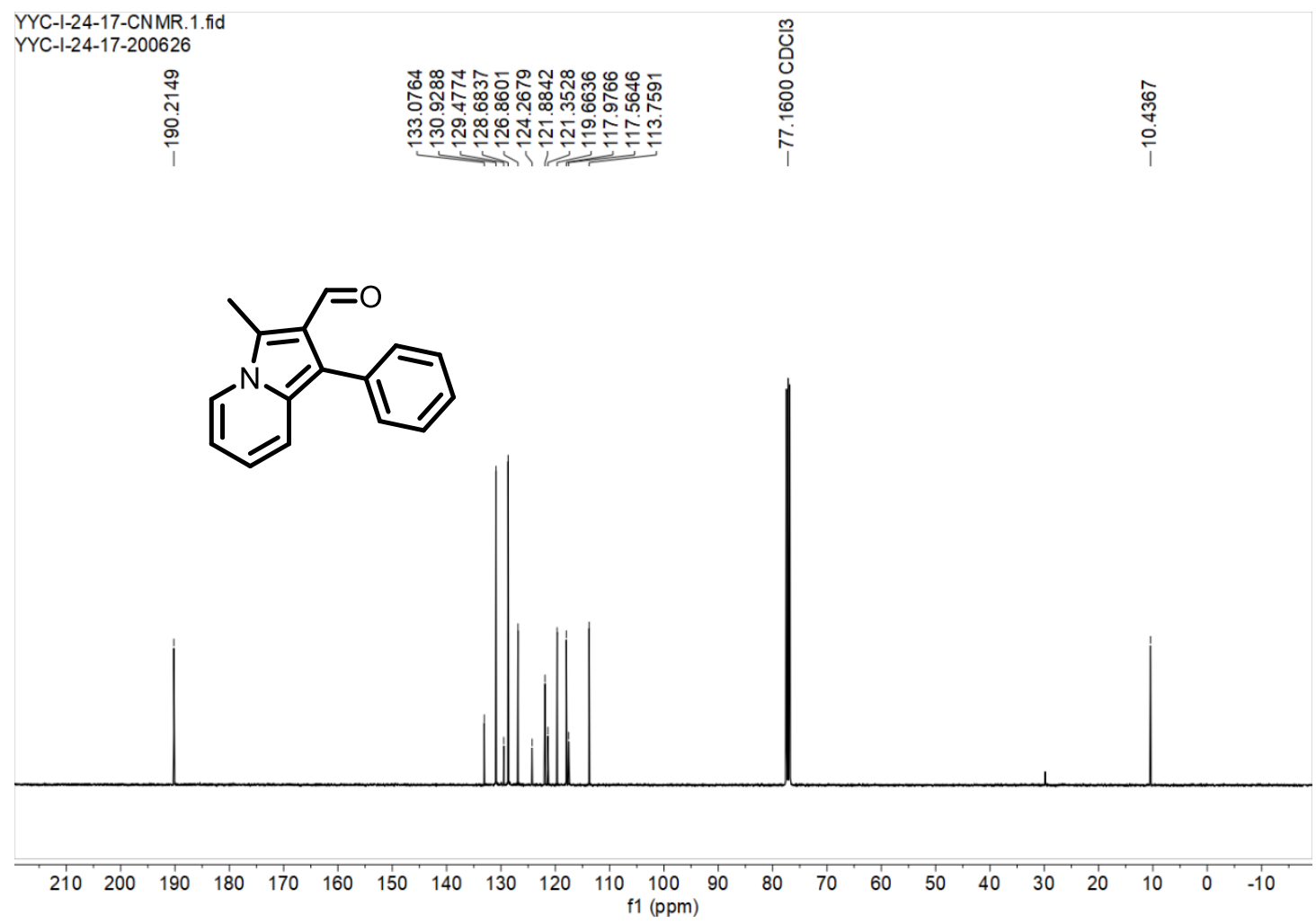

Figure $\mathrm{S} 2{ }^{13} \mathrm{C}\left\{{ }^{1} \mathrm{H}\right\} \mathrm{NMR}\left(101 \mathrm{MHz}, \mathrm{CDCl}_{3}\right)$ of compound 3a 


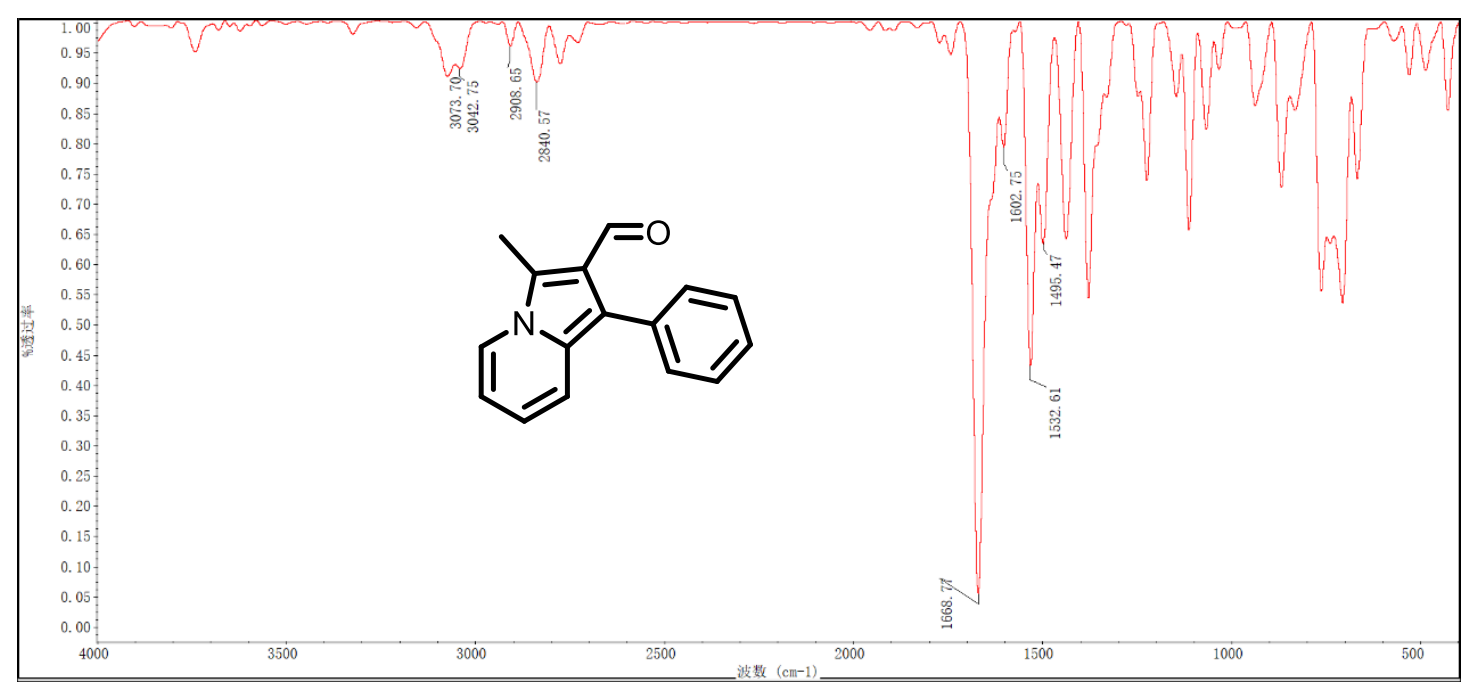

Figure S3 IR spectra of compound Ba.

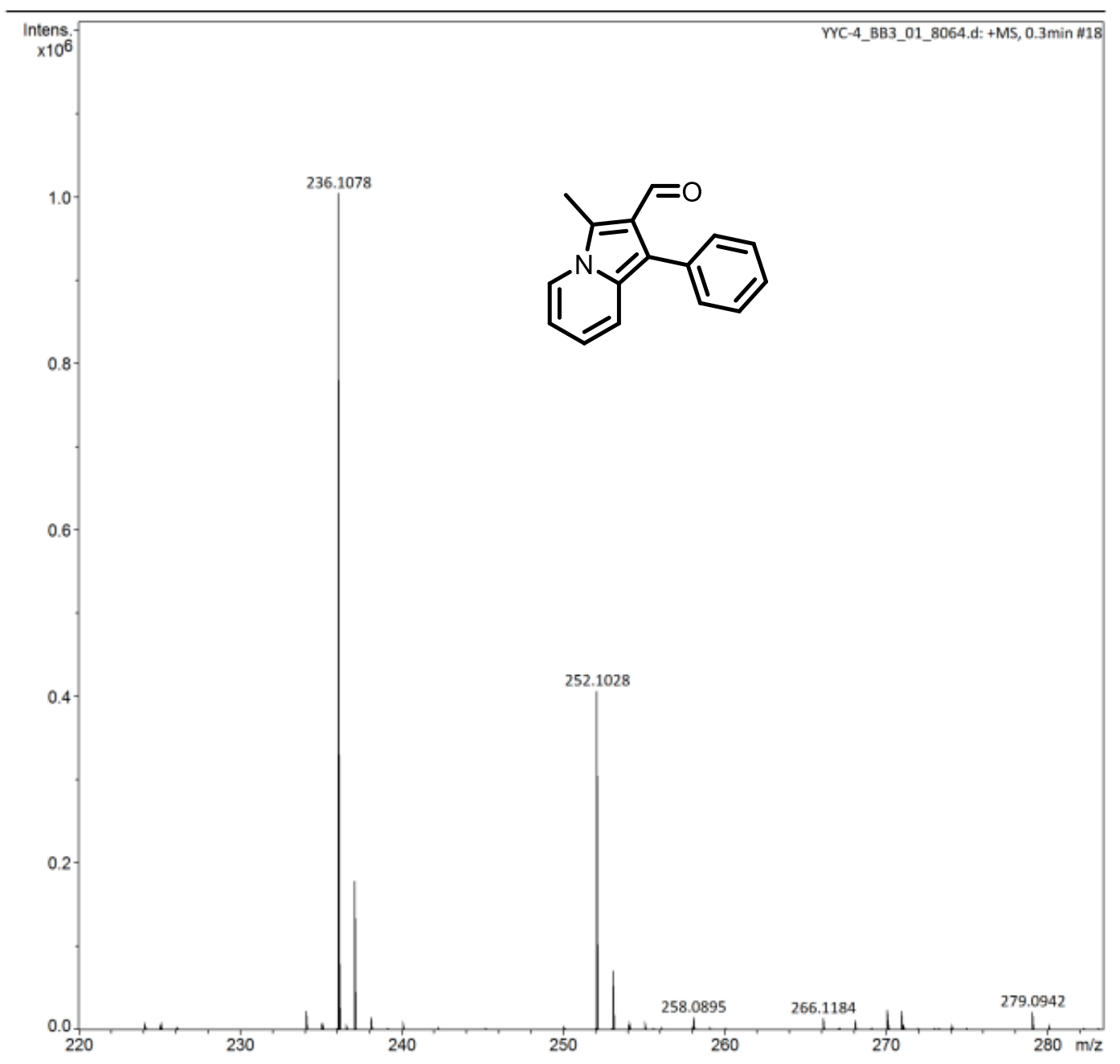

Figure S4 HRMS spectra of compound Ba.

S3 


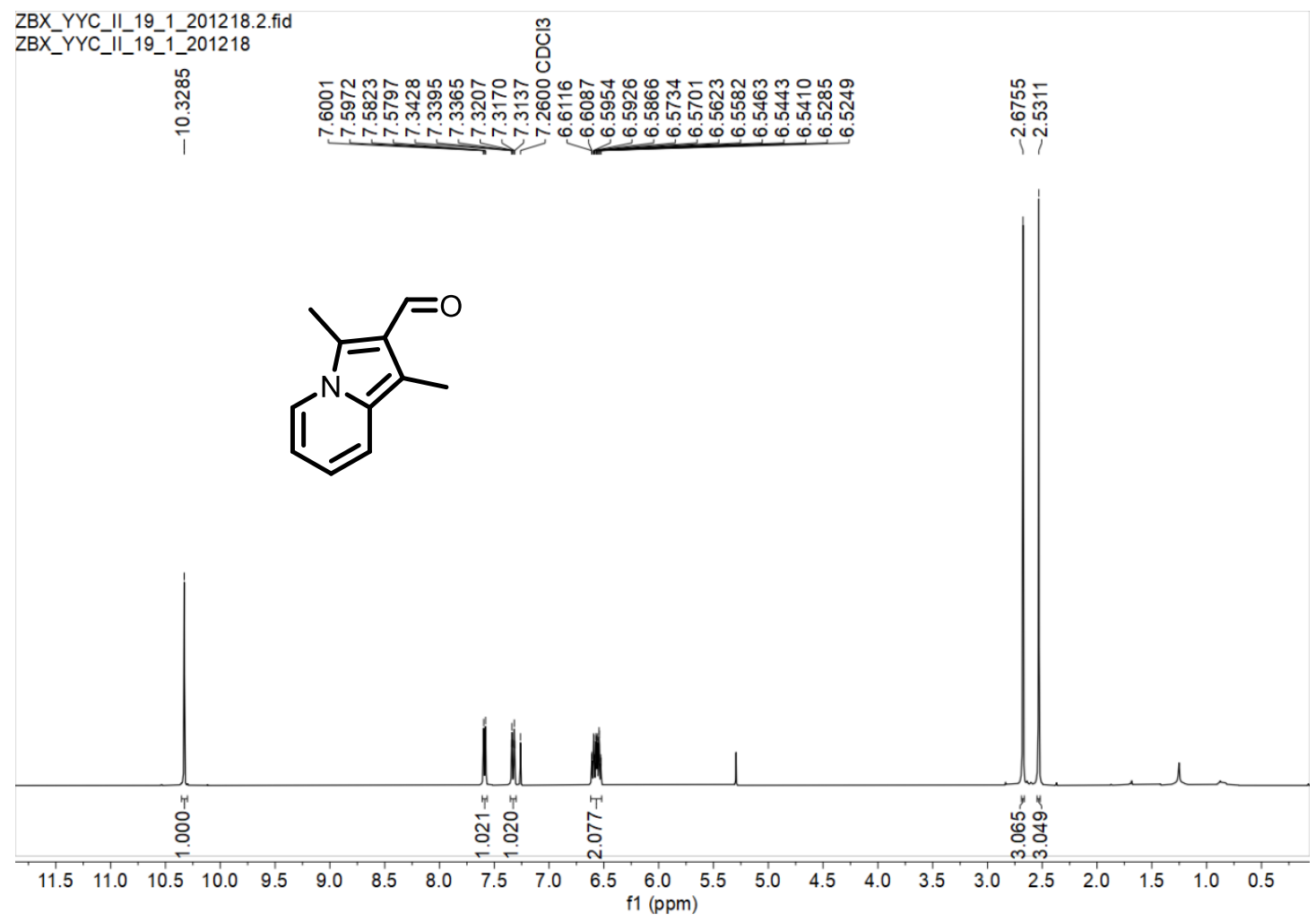

Figure $\mathrm{S} 5{ }^{1} \mathrm{H}$ NMR $\left(400 \mathrm{MHz}, \mathrm{CDCl}_{3}\right.$ ) of compound $\mathbf{3 b}$.

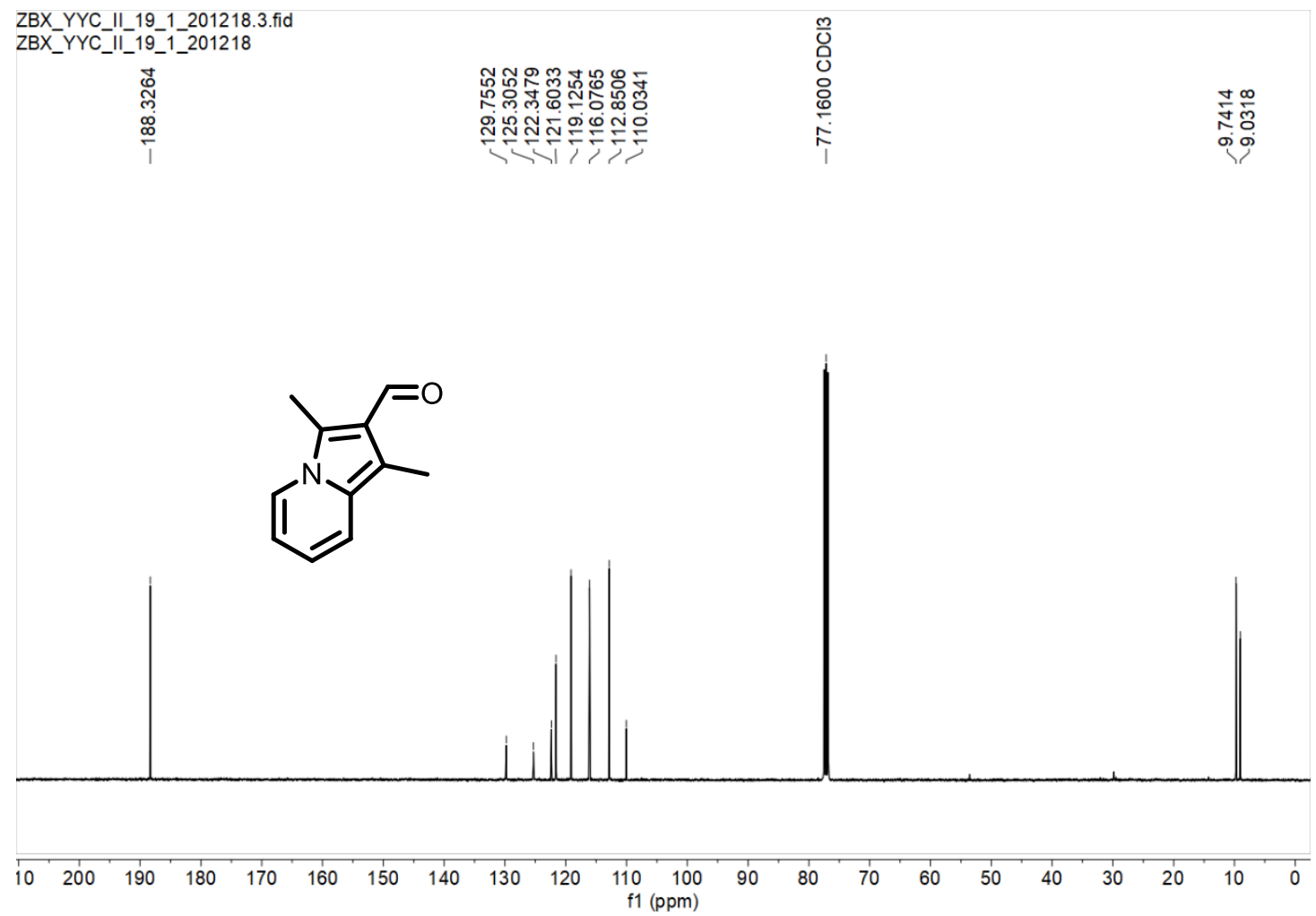

Figure $\mathrm{S} 6{ }^{13} \mathrm{C}\left\{{ }^{1} \mathrm{H}\right\}$ NMR (101 MHz, $\left.\mathrm{CDCl}_{3}\right)$ of compound $\mathbf{3 b}$. 


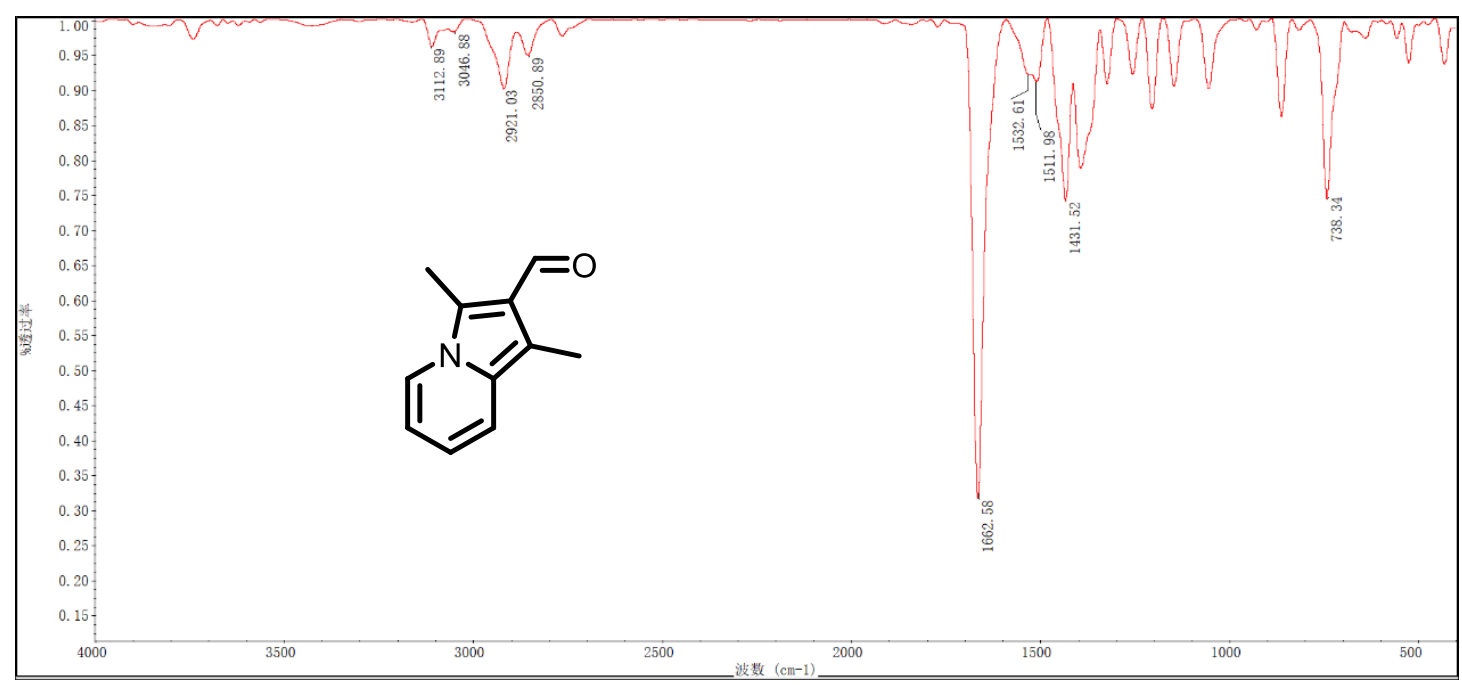

Figure S7 IR spectra of compound $\mathbf{3 b}$.

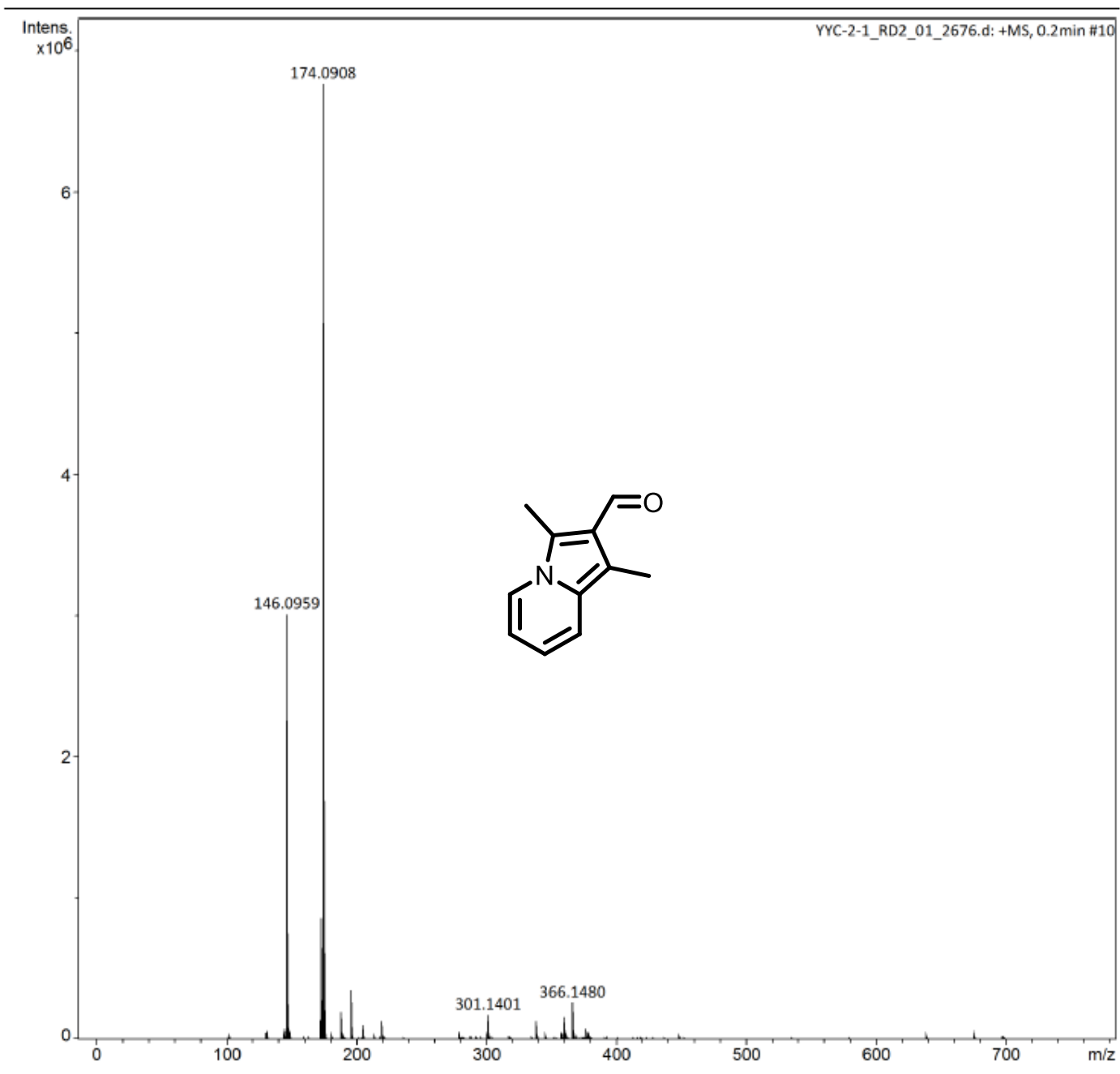

Figure S8 HRMS spectra of compound $\mathbf{3 b}$. 


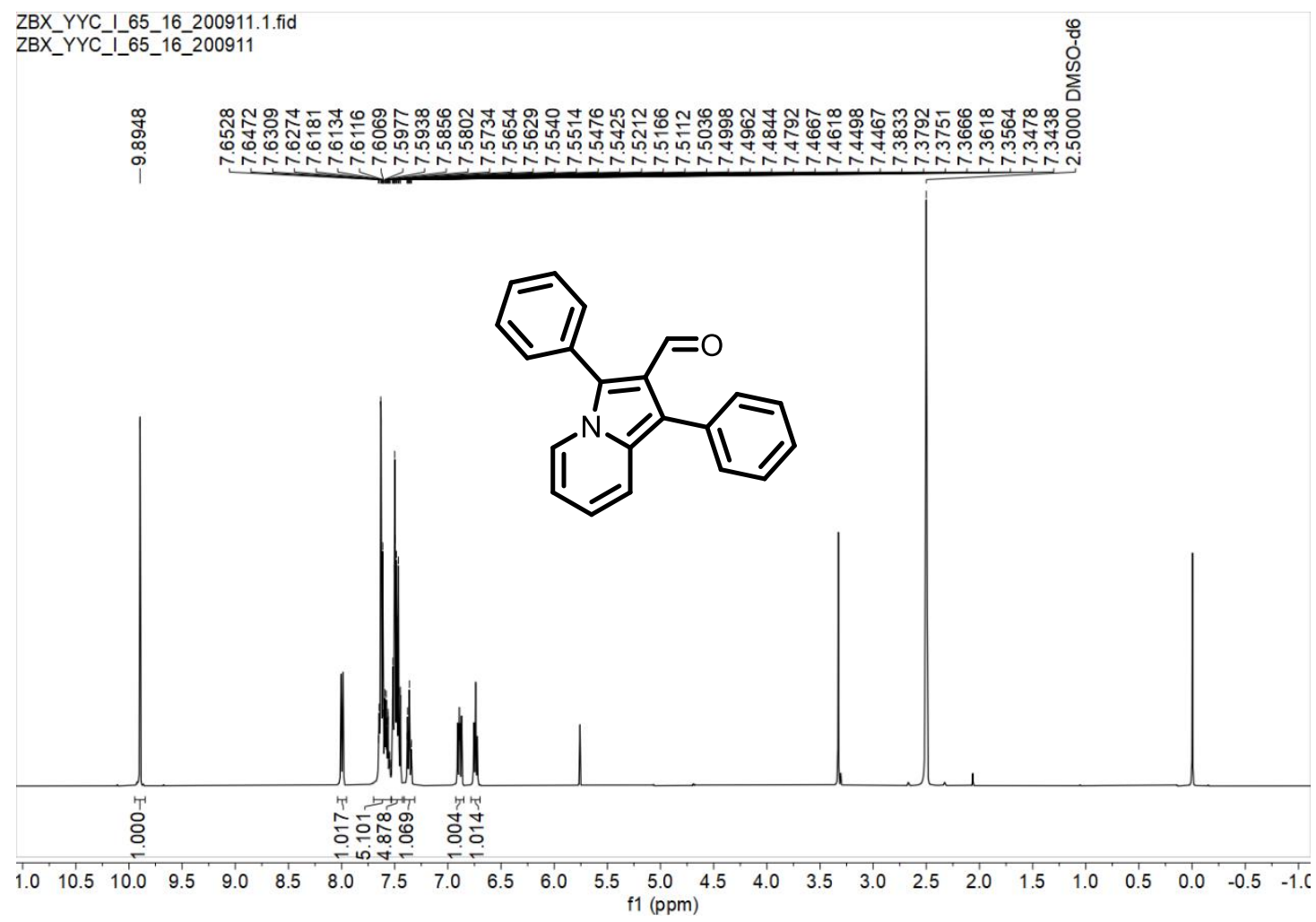

Figure S9 ${ }^{1} \mathrm{H}$ NMR (400 MHz, DMSO- $d_{6}$ ) of compound $3 \mathbf{c}$.

ZBX_YYC_1_65_16_200915.1.fid ZBX_YYC_165_16_200915

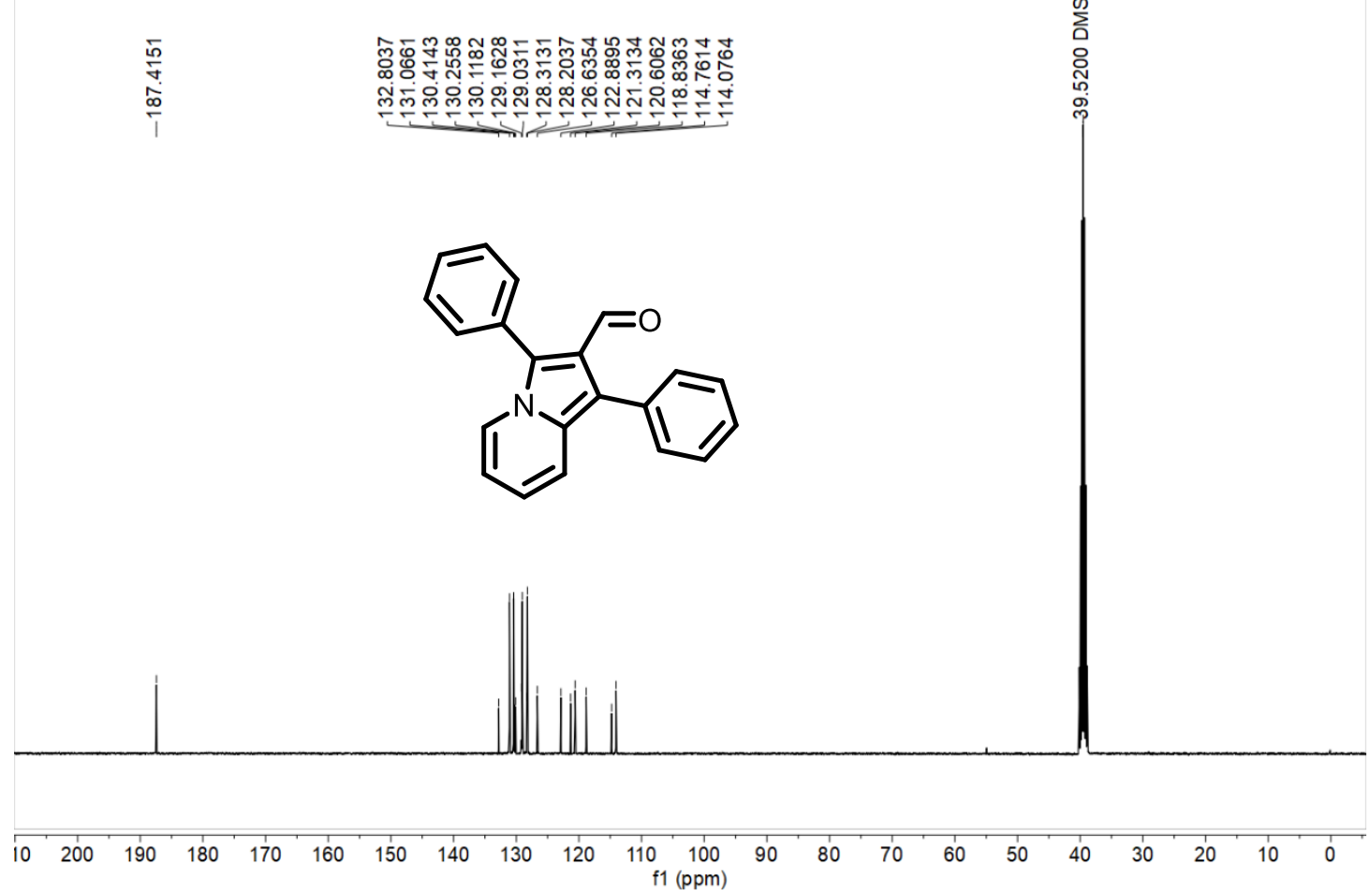

Figure $\mathrm{S} 10{ }^{13} \mathrm{C}\left\{{ }^{1} \mathrm{H}\right\}$ NMR (101 MHz, DMSO- $d_{6}$ ) of compound 3c 


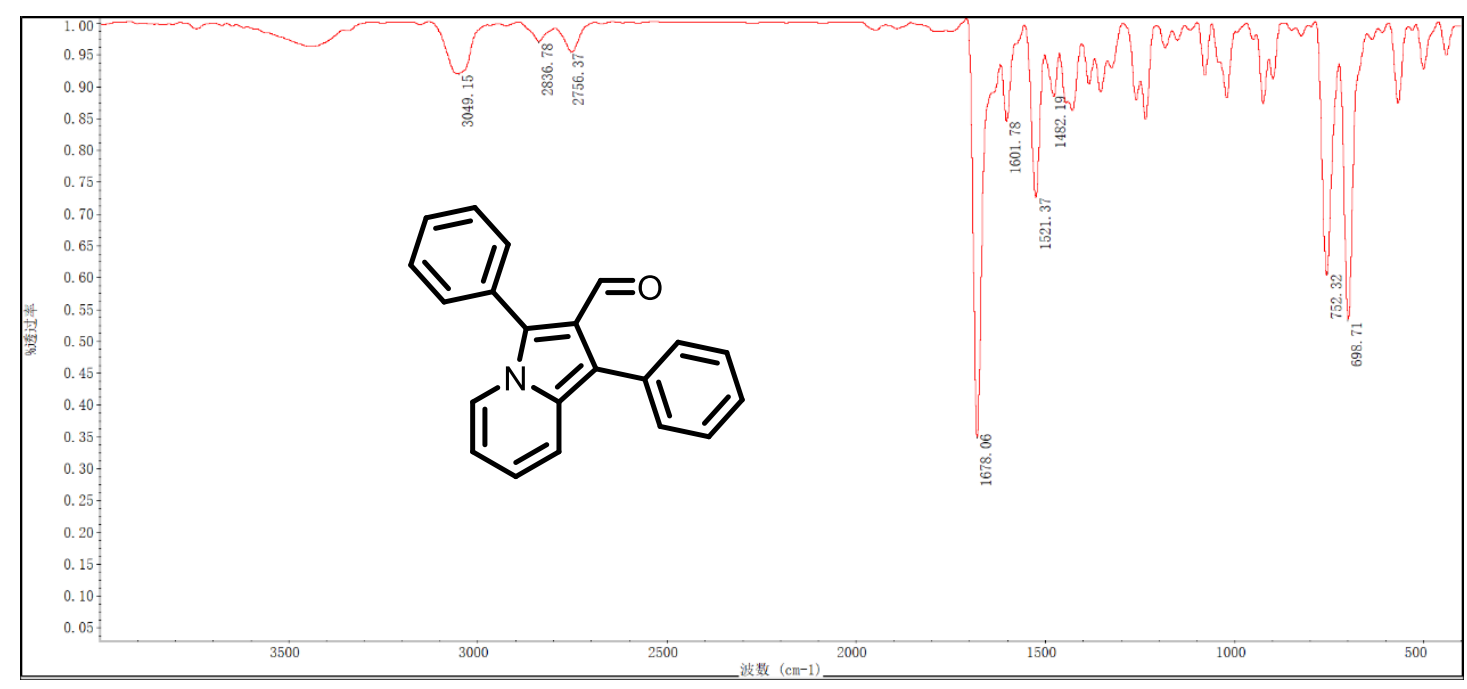

Figure S11 IR spectra of compound Bc.

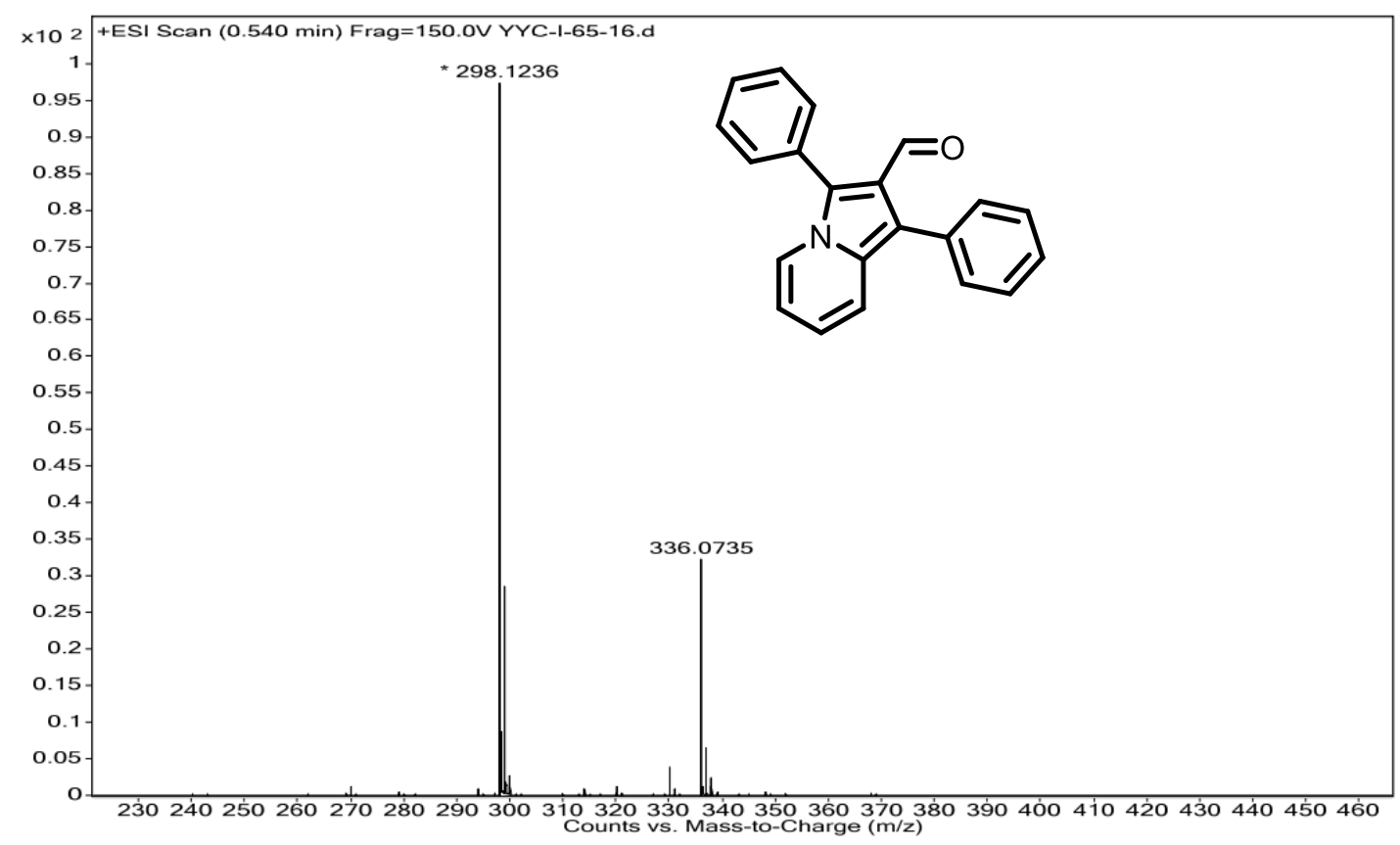

Figure S12 HRMS spectra of compound Bc

ST 


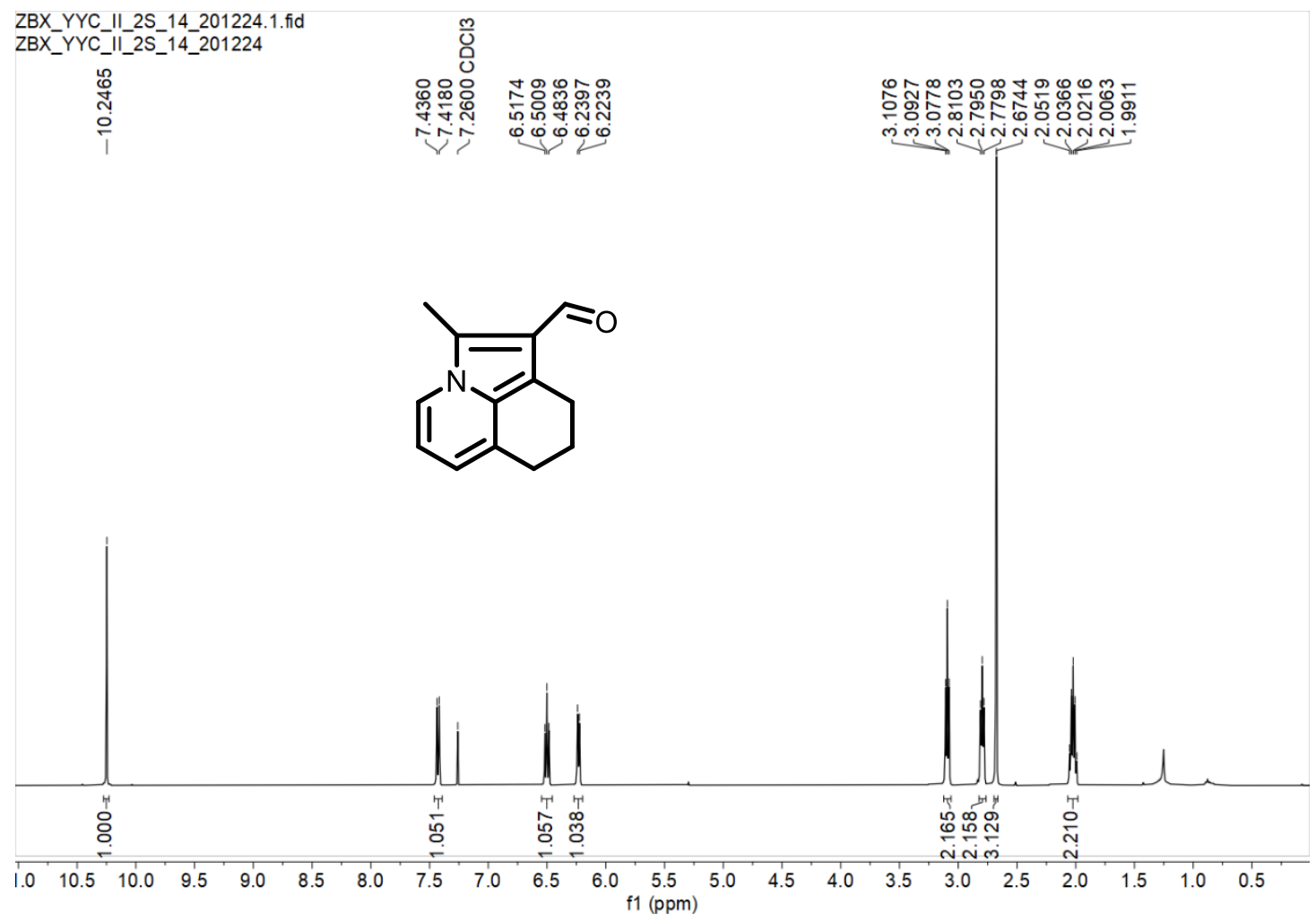

Figure $\mathrm{S} 13{ }^{1} \mathrm{H}$ NMR $\left(400 \mathrm{MHz}, \mathrm{CDCl}_{3}\right)$ of compound 3d

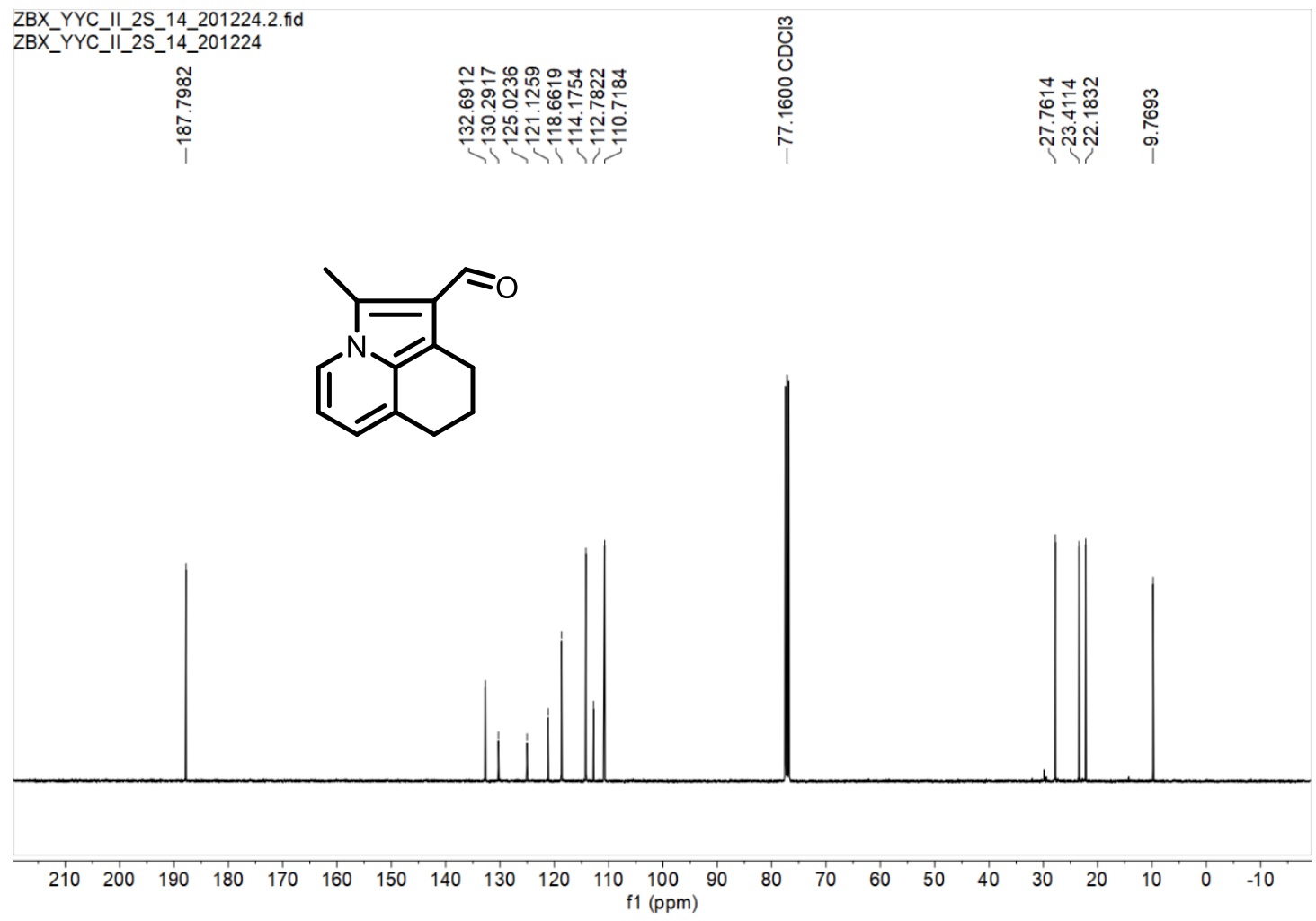

Figure $\mathrm{S} 14{ }^{13} \mathrm{C}\left\{{ }^{1} \mathrm{H}\right\}$ NMR (101 MHz, $\left.\mathrm{CDCl}_{3}\right)$ of compound 3d 


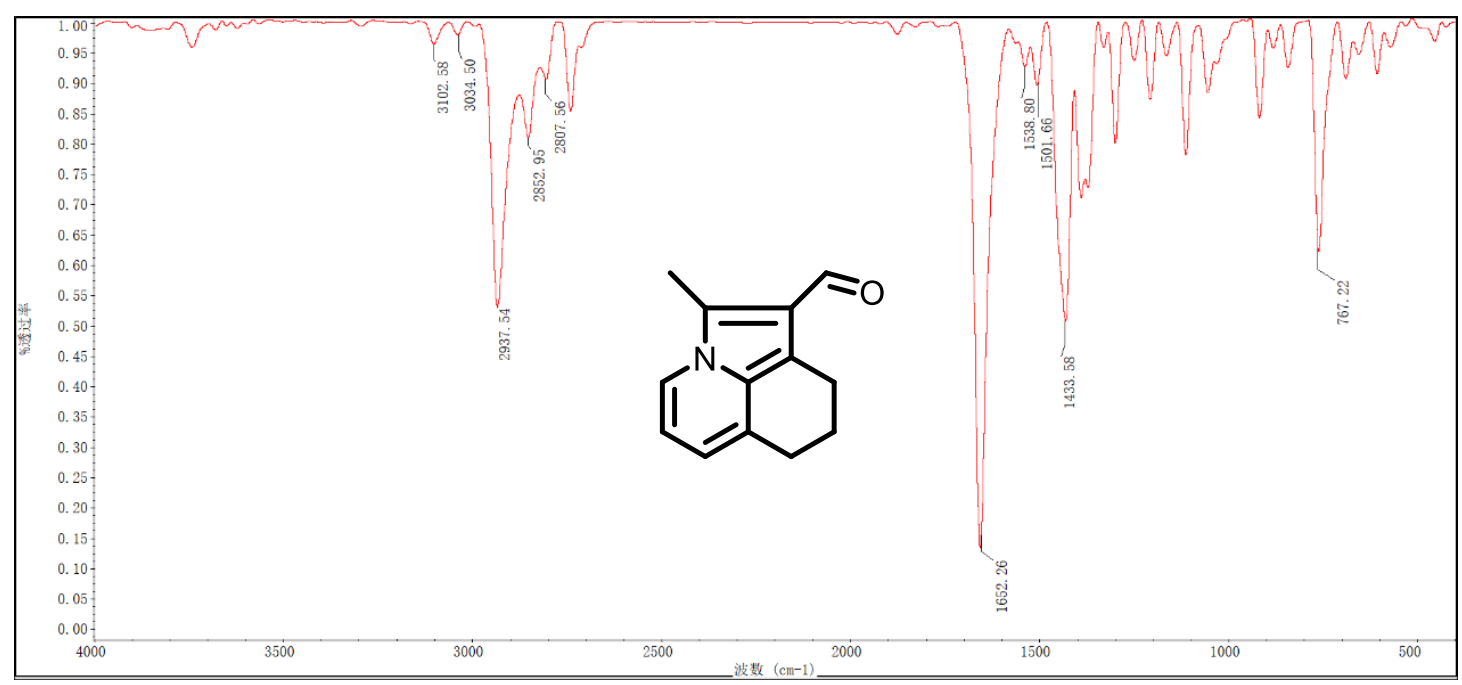

Figure S15 IR spectra of compound 3d

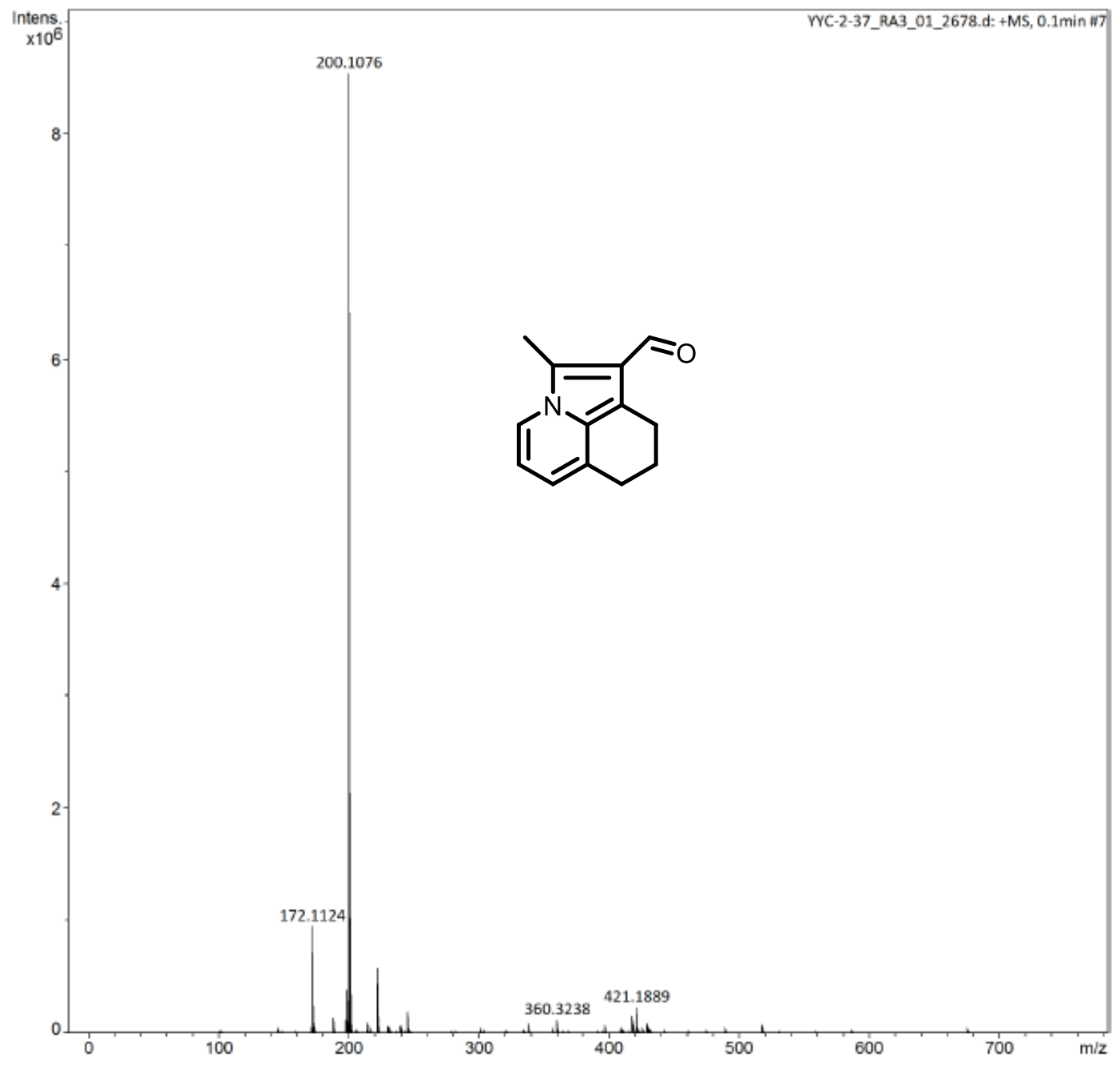

Figure S16 HRMS spectra of compound 3d 


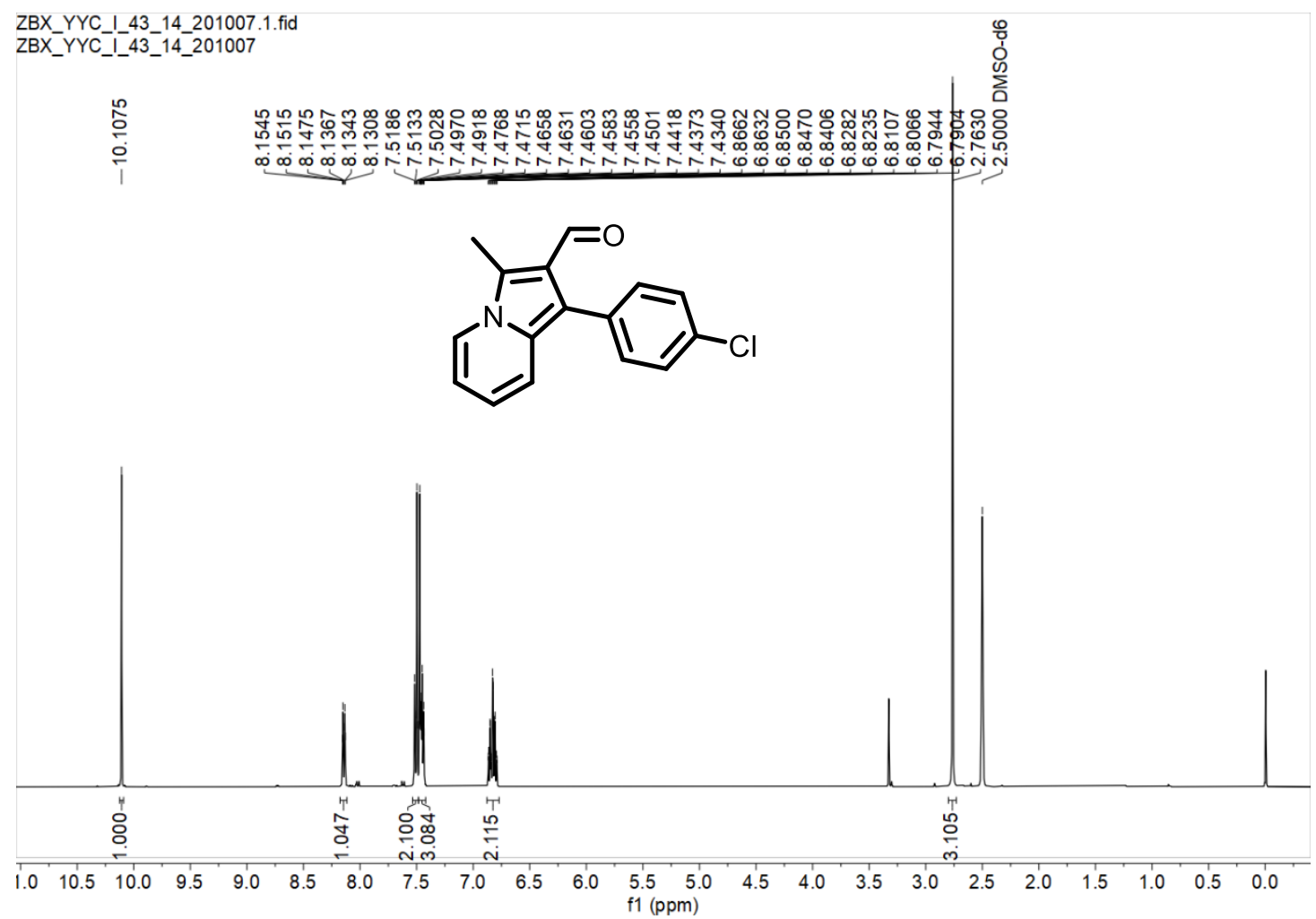

Figure S17 ${ }^{1} \mathrm{H}$ NMR (400 MHz, DMSO- $d_{6}$ ) of compound $3 \mathbf{e}$

ZBX_YYC_I_43_14_2012013.1. fid ZBX_YYC_I_43_14_2012013

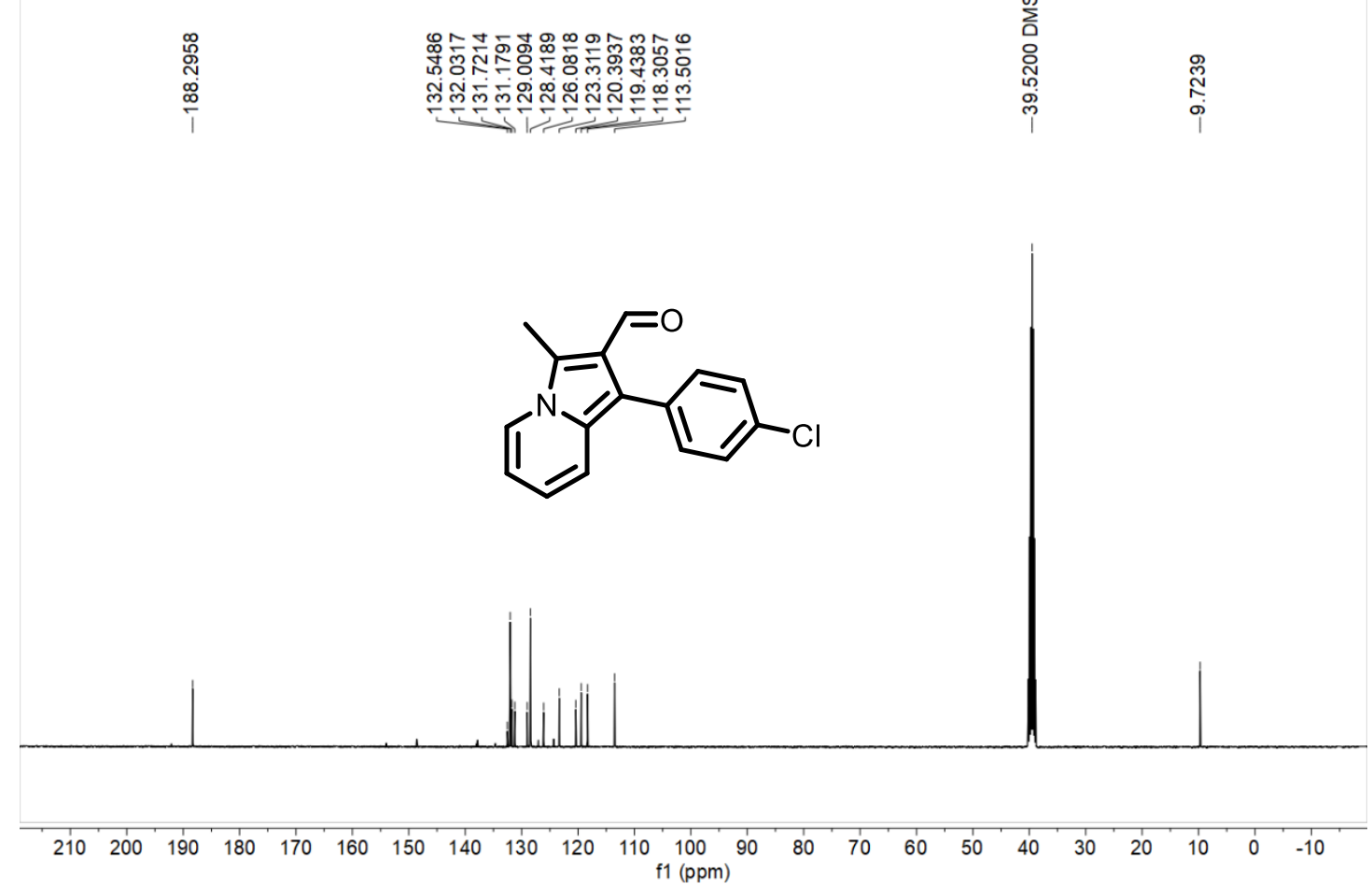

Figure $\mathrm{S} 18{ }^{13} \mathrm{C}\left\{{ }^{1} \mathrm{H}\right\}$ NMR (101 MHz, DMSO- $\left.d_{6}\right)$ of compound 3e 


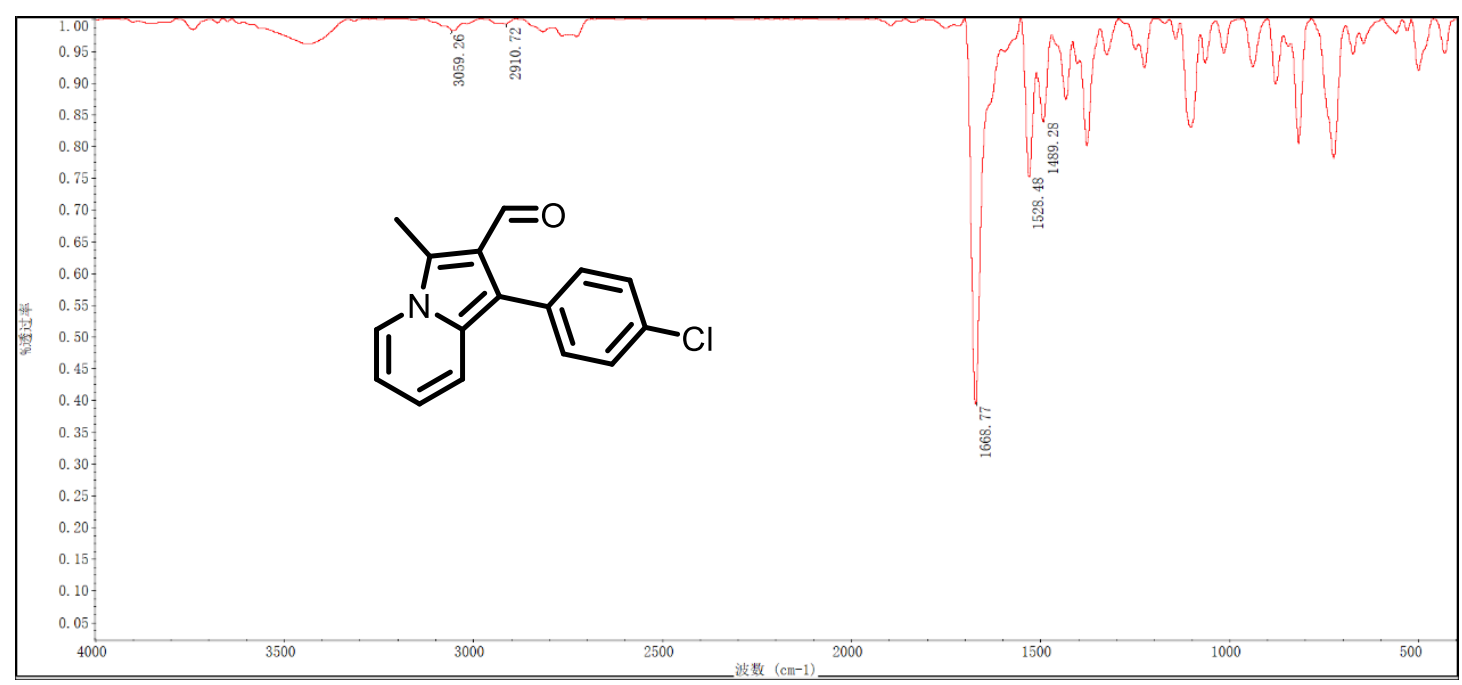

Figure S19 IR spectra of compound 3e

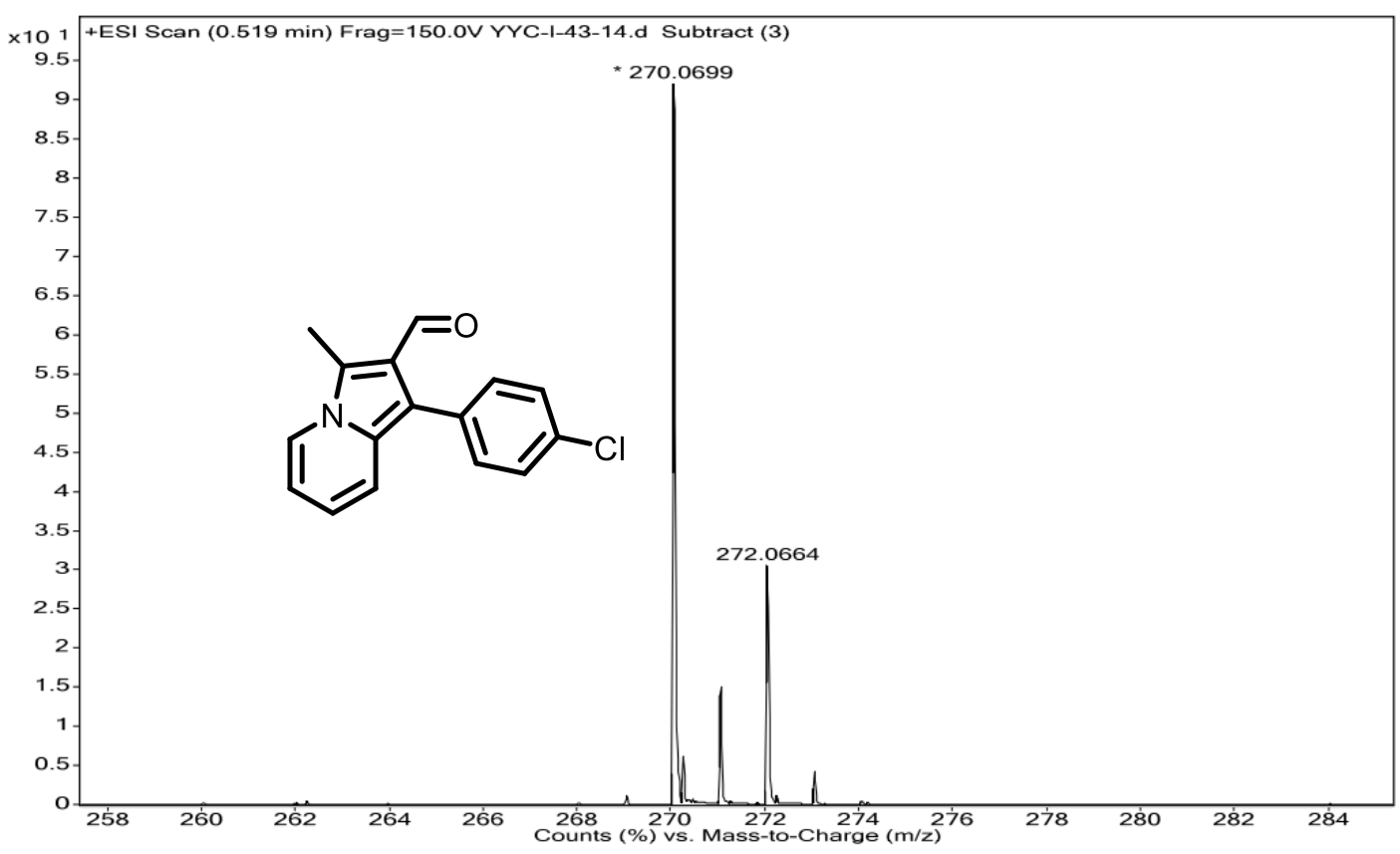

Figure S20 HRMS spectra of compound 3e 


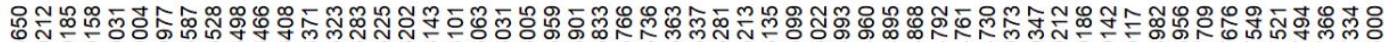
ळ

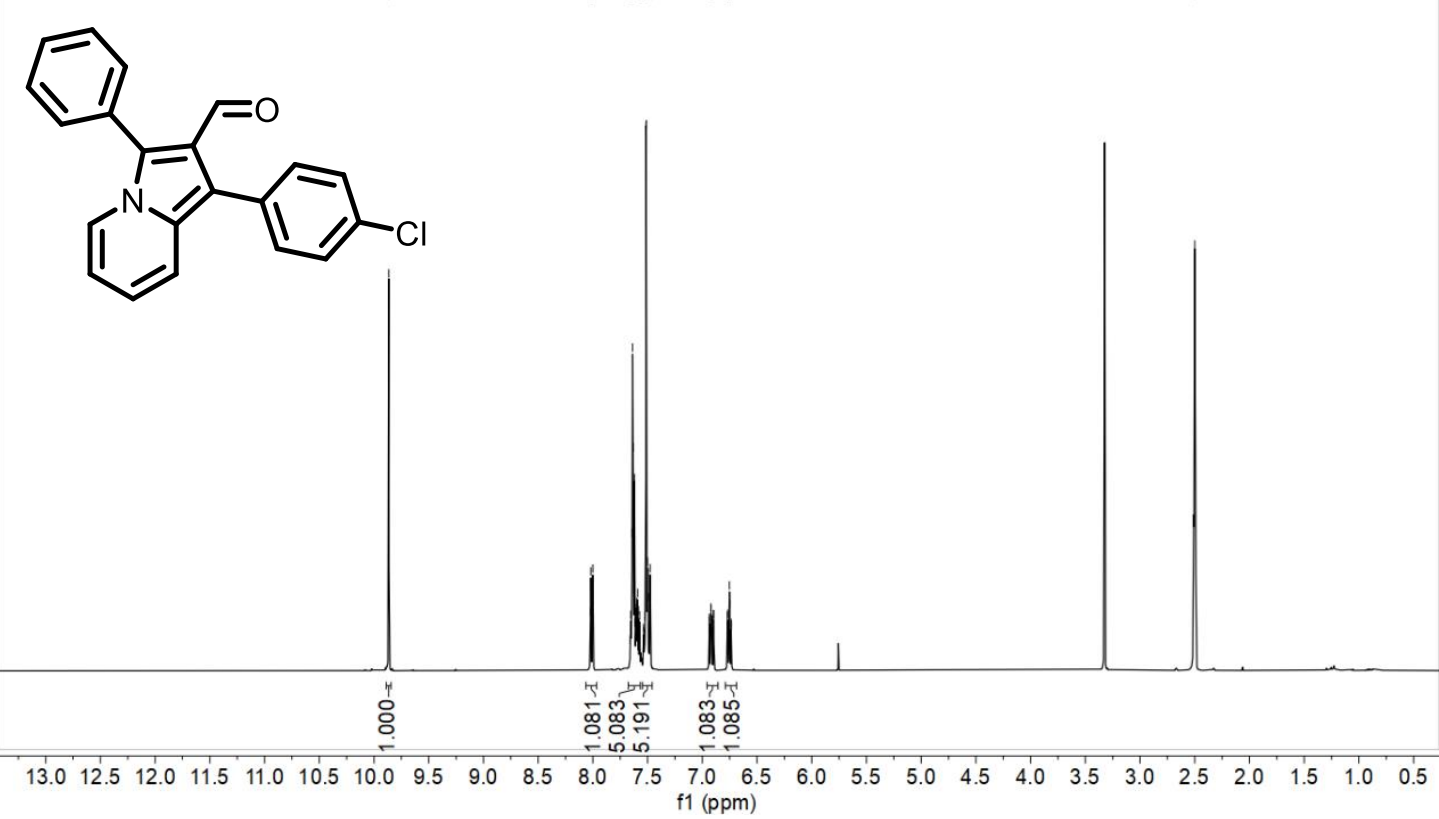

Figure S2 $1{ }^{1} \mathrm{H}$ NMR $\left(400 \mathrm{MHz}\right.$, DMSO- $\left.d_{6}\right)$ of compound $\mathbf{3 f}$

ZBX_YYC_I_71_11_200924.1.fid

ZBX_YYC_I_71_11_200924

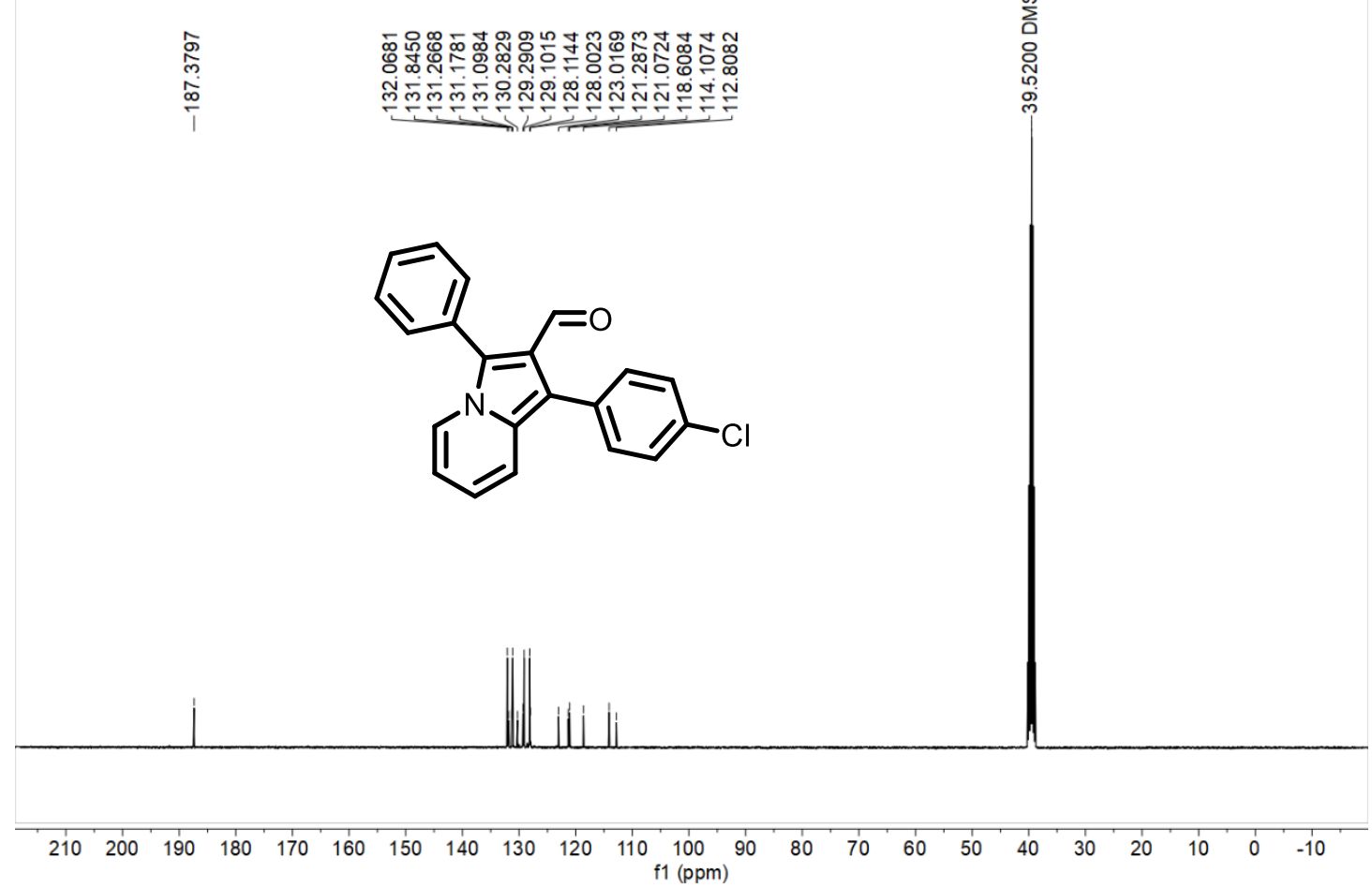

Figure S22 ${ }^{13} \mathrm{C}\left\{{ }^{1} \mathrm{H}\right\}$ NMR (101 MHz, DMSO- $\left.d_{6}\right)$ of compound $\mathbf{3 f}$ 


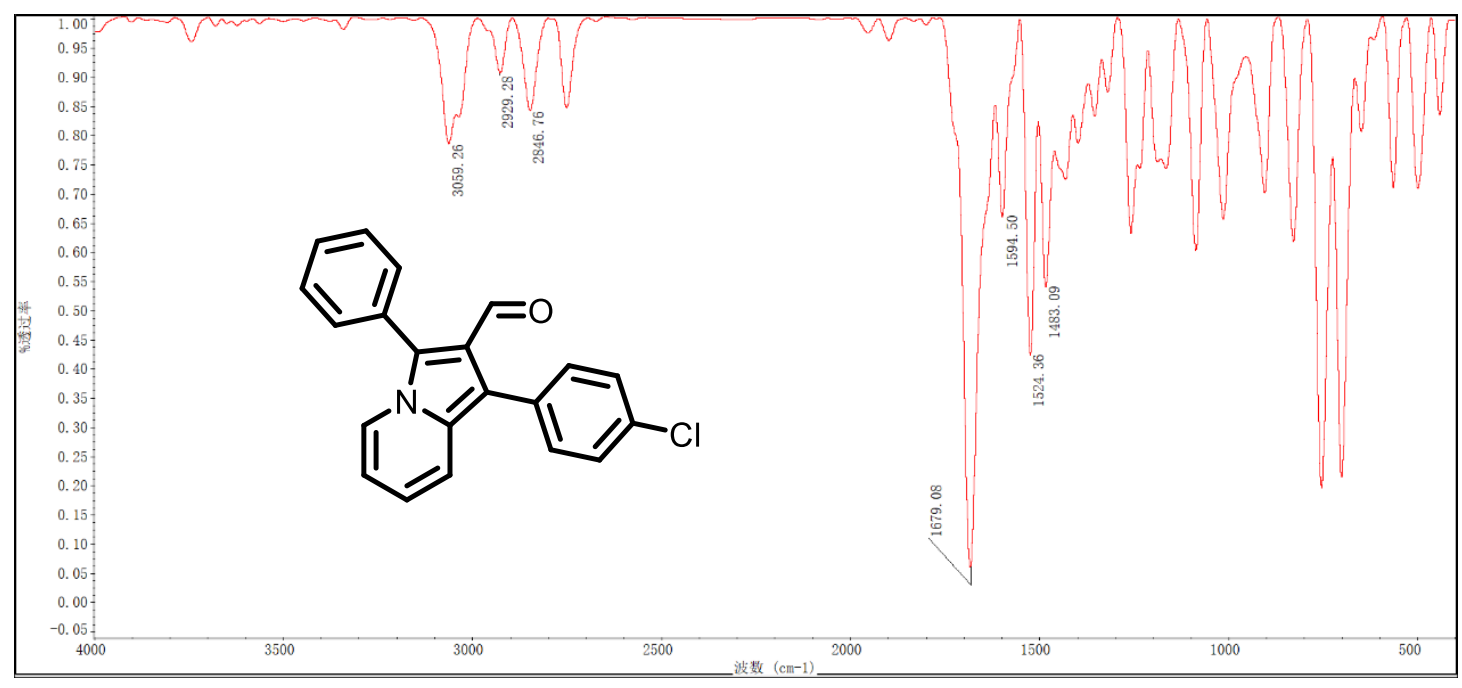

Figure S23 IR spectra of compound $\mathbf{3 f}$

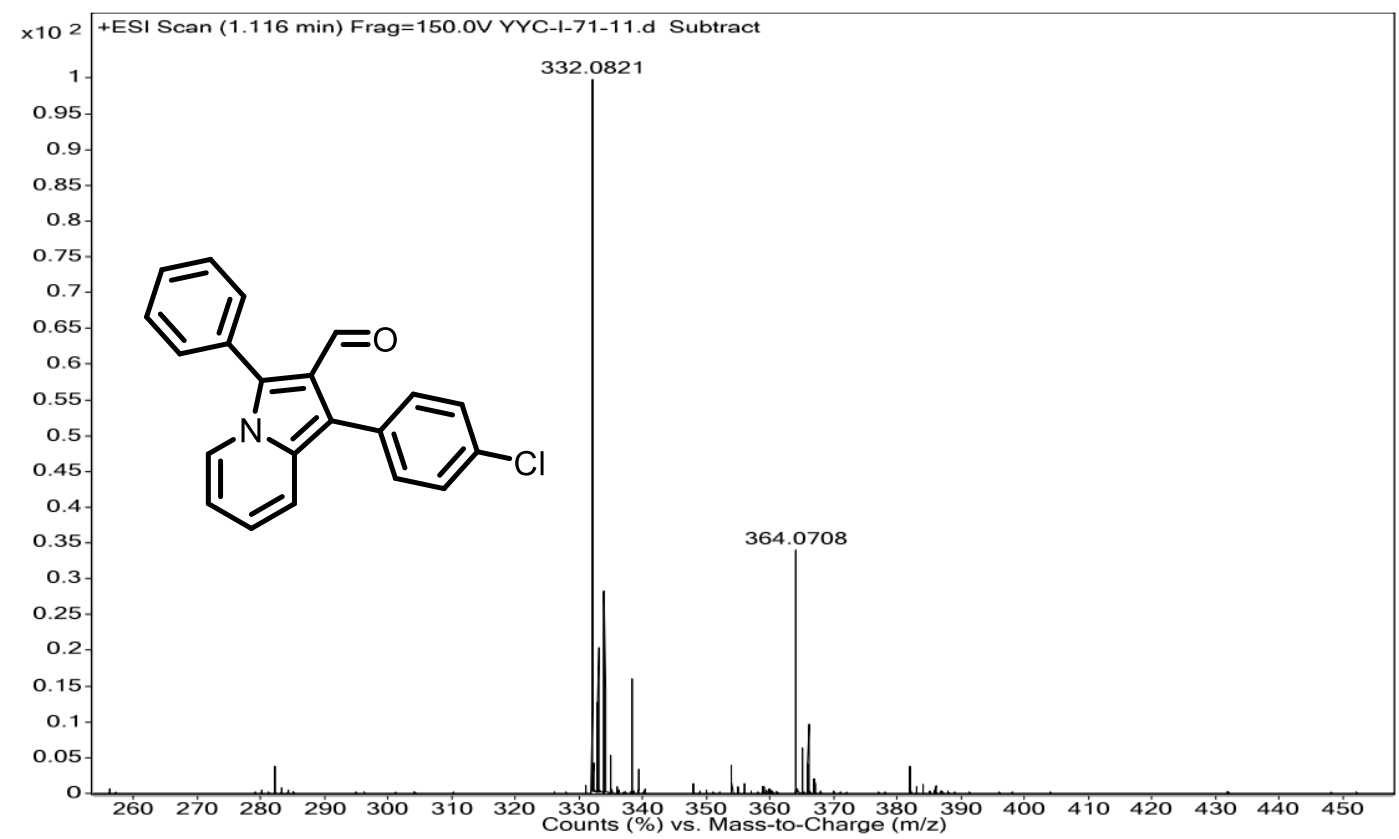

Figure S24 HRMS spectra of compound $\mathbf{3 f}$ 


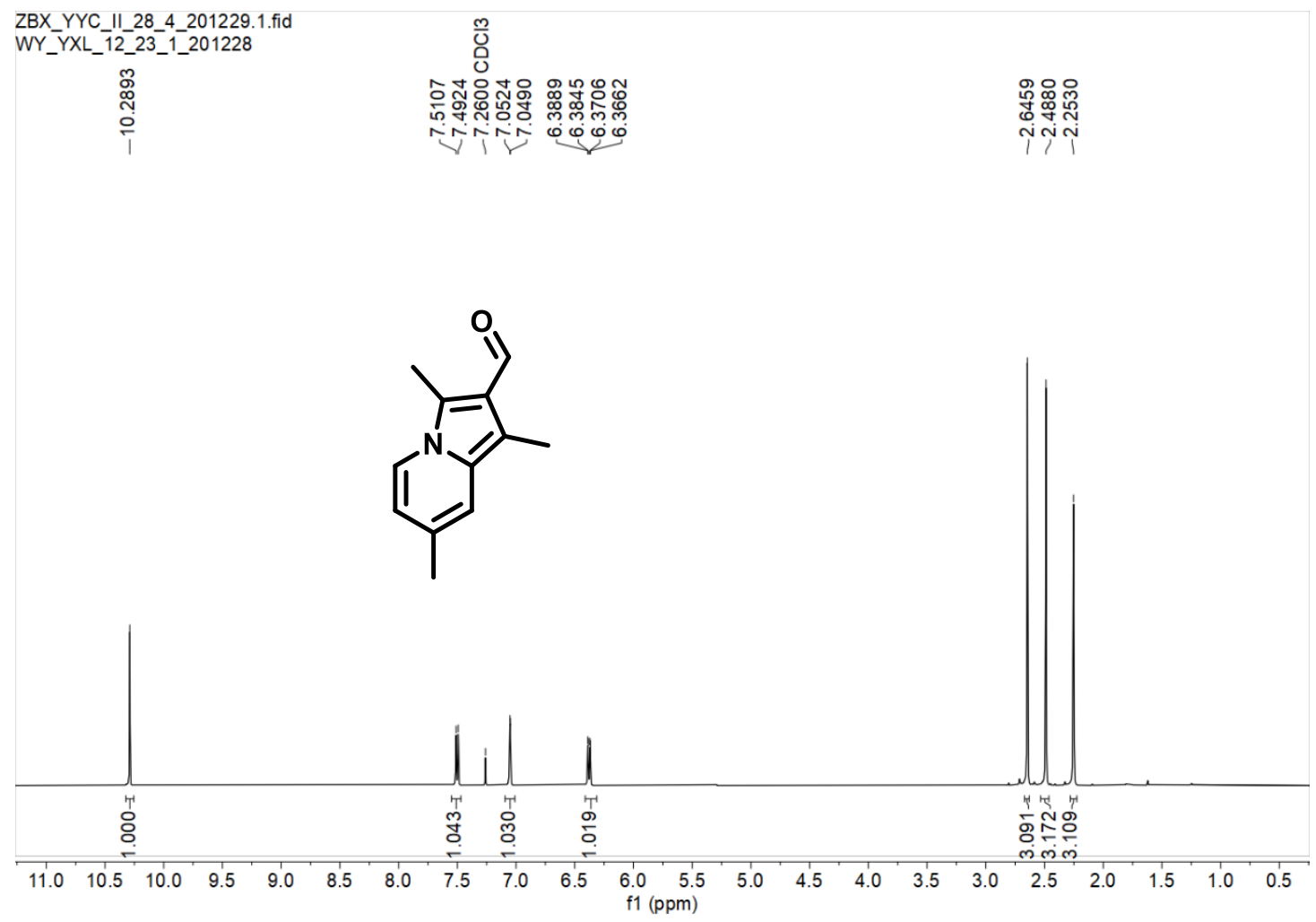

Figure $\mathrm{S} 25{ }^{1} \mathrm{H}$ NMR $\left(400 \mathrm{MHz}, \mathrm{CDCl}_{3}\right)$ of compound $\mathbf{3 g}$

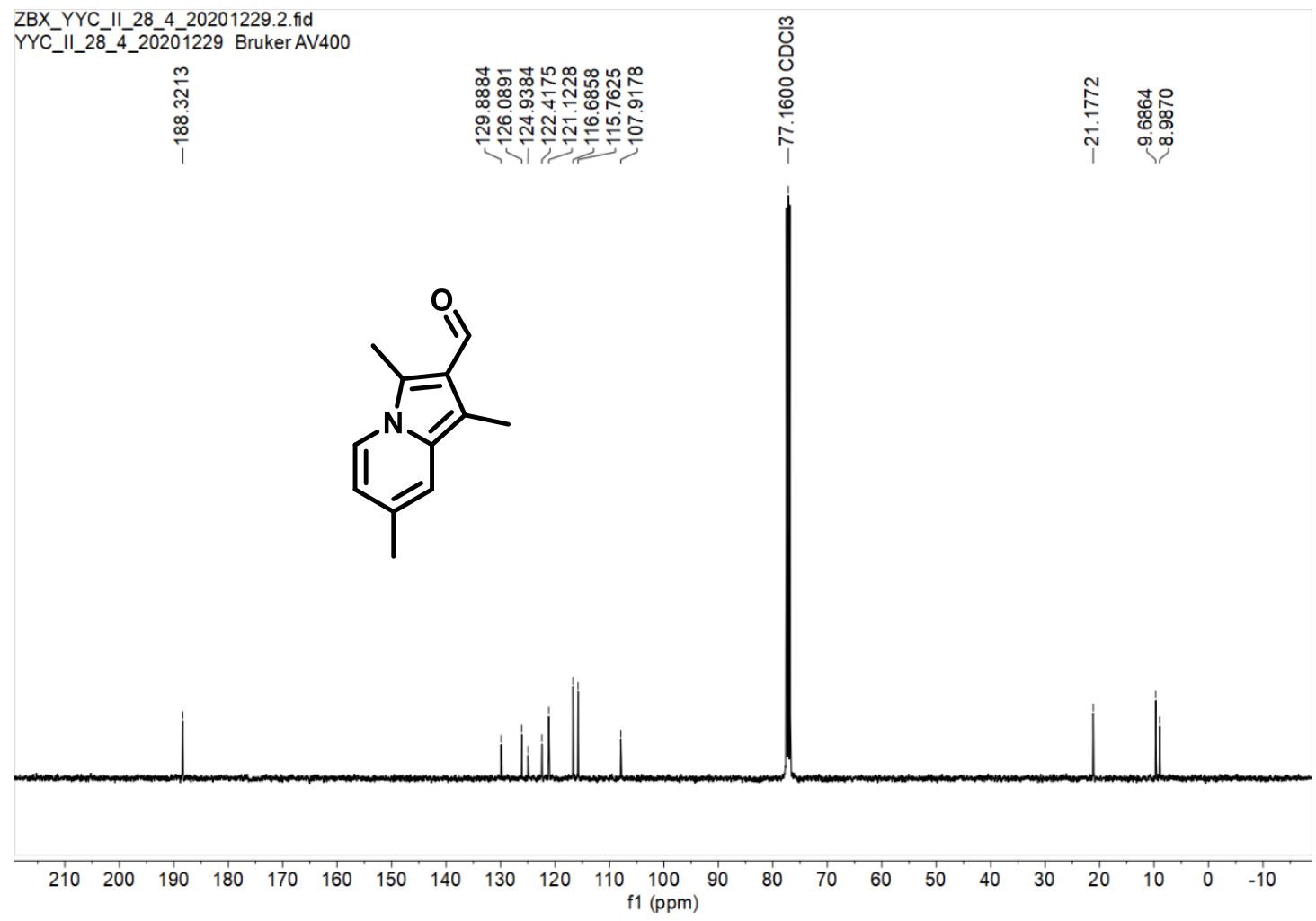

Figure $\mathrm{S} 26{ }^{13} \mathrm{C}\left\{{ }^{1} \mathrm{H}\right\}$ NMR $\left(101 \mathrm{MHz}, \mathrm{CDCl}_{3}\right)$ of compound $\mathbf{3 g}$ 


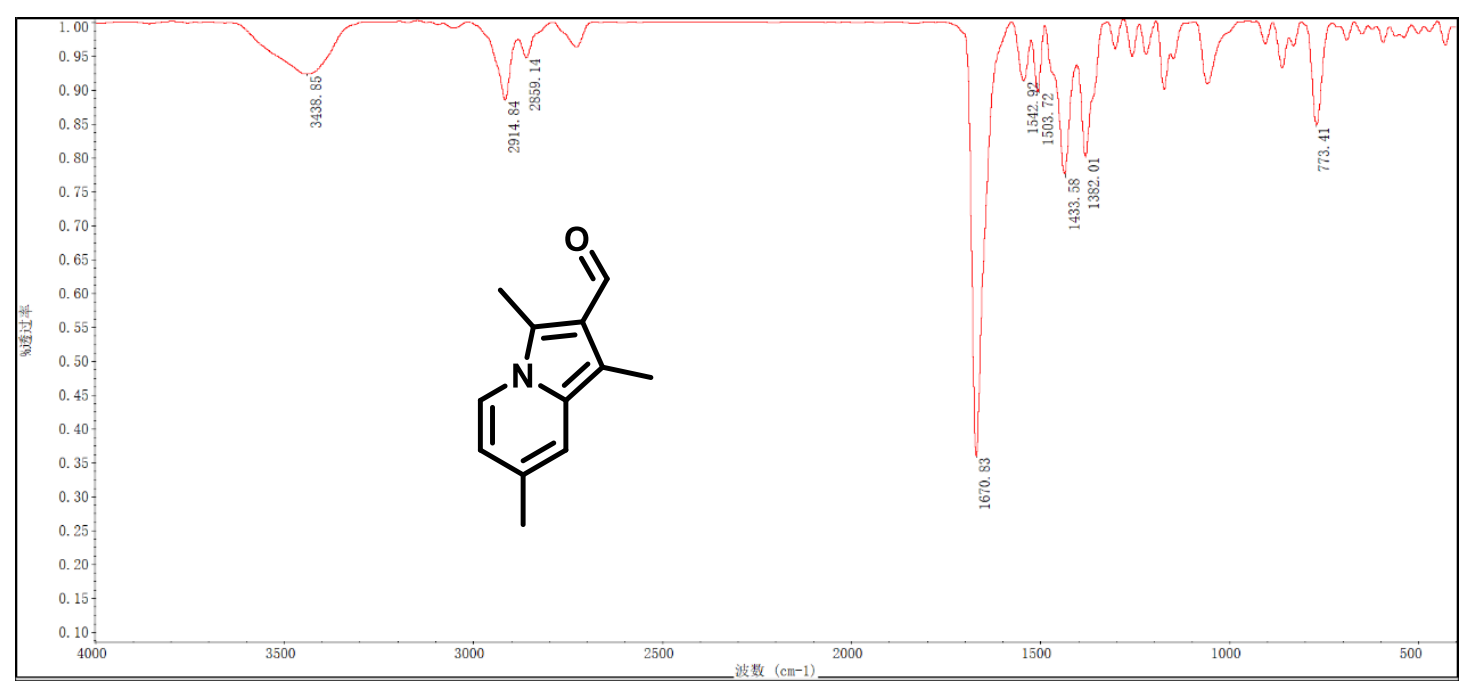

Figure S27 IR spectra of compound 3g

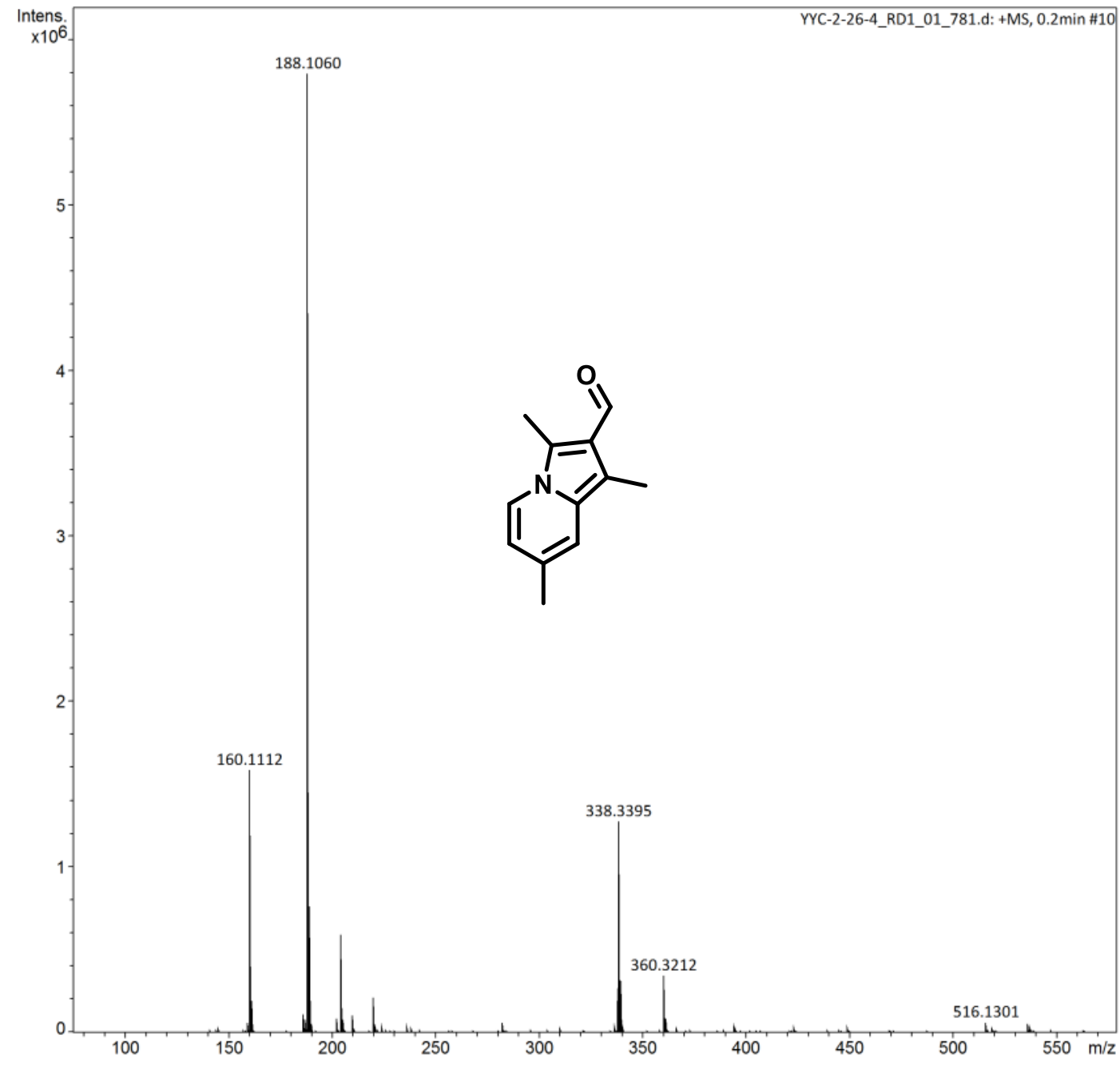

Figure S28 HRMS spectra of compound $\mathbf{3 g}$ 


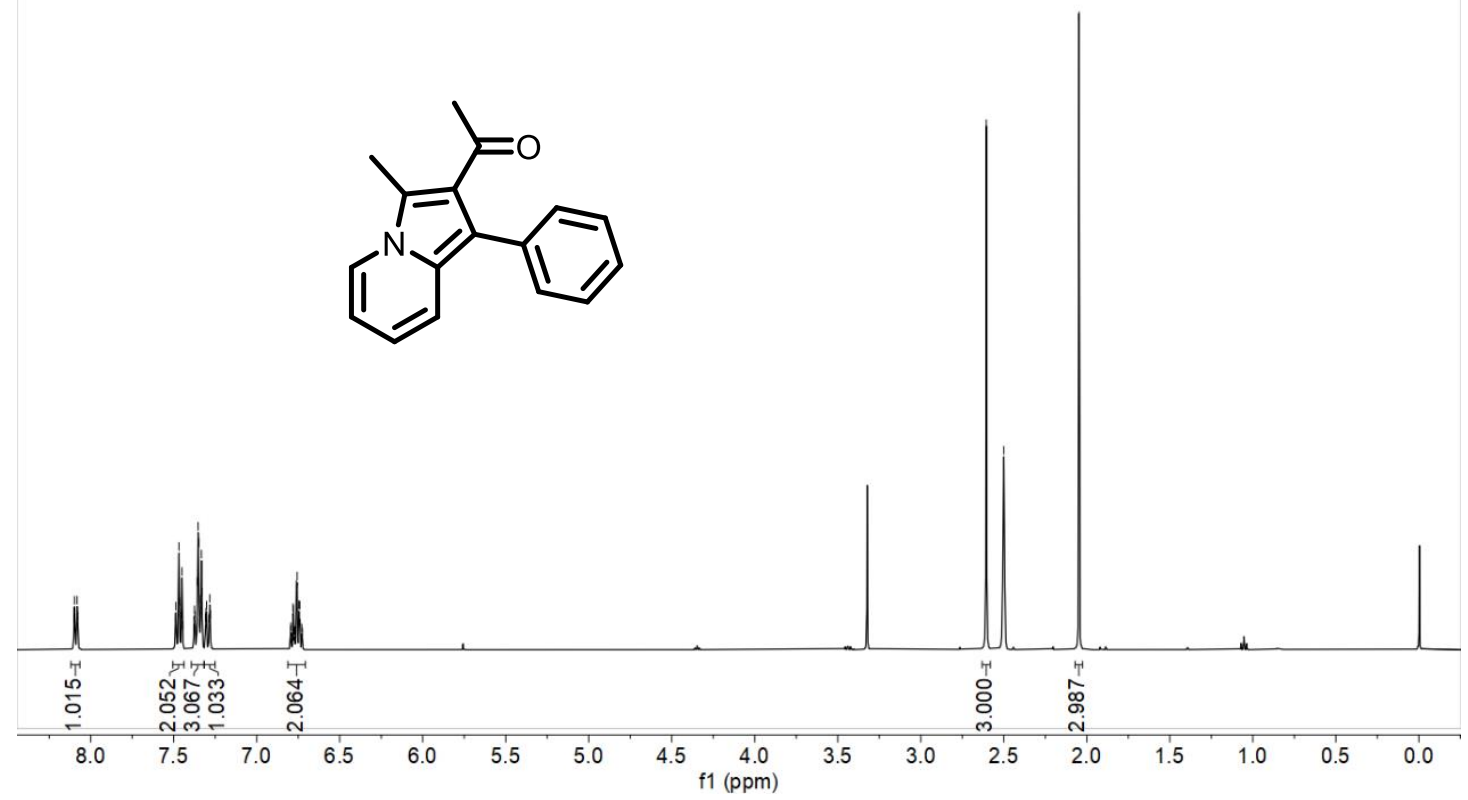

Figure S29 ${ }^{1} \mathrm{H}$ NMR (400 MHz, DMSO- $d_{6}$ ) of compound $\mathbf{3 h}$

ZBX_YYC_I_40_15_2012013.1.fid ZBX_YYC_I_40_15_2012013

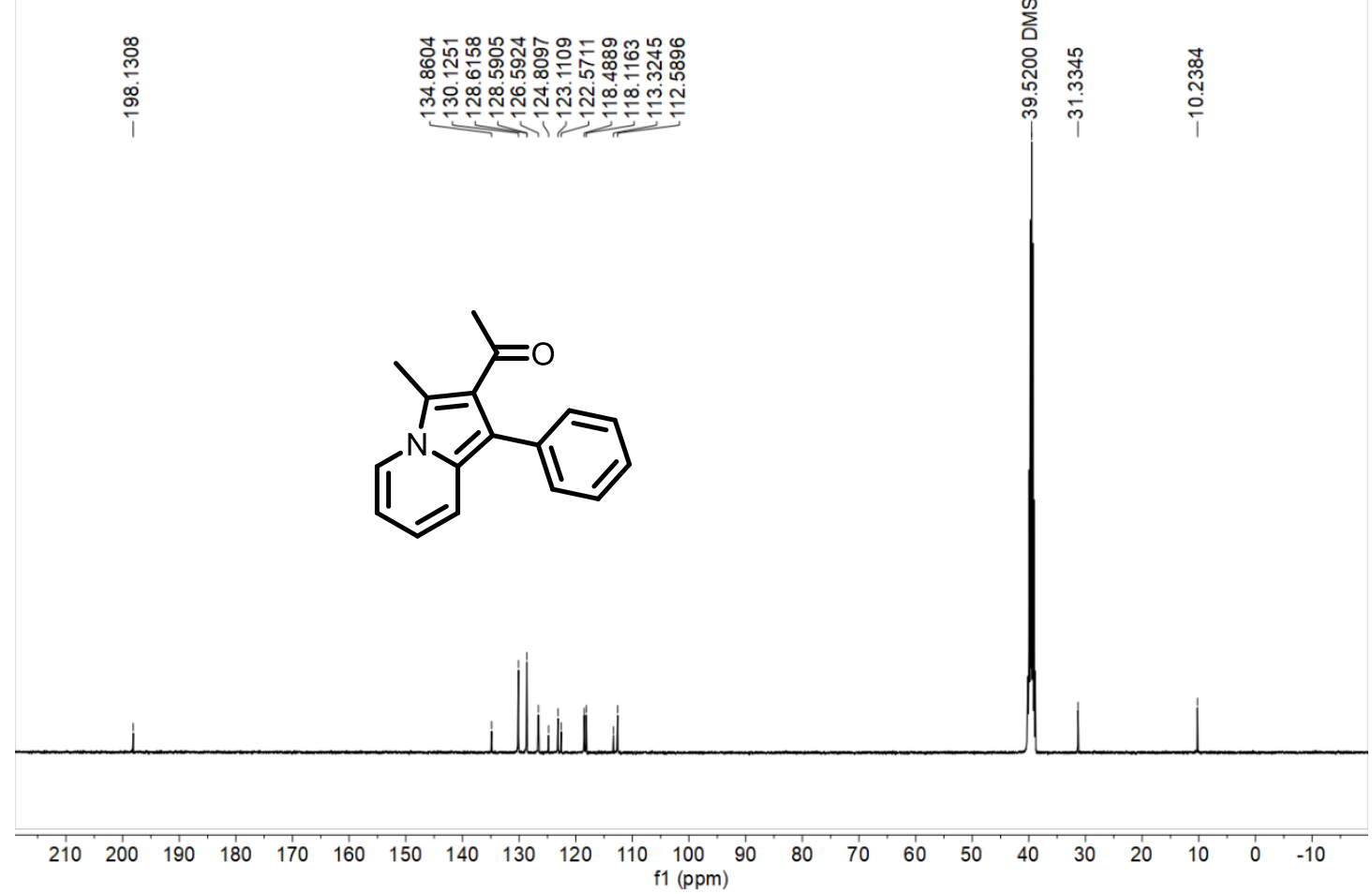

Figure $\mathrm{S} 30{ }^{13} \mathrm{C}\left\{{ }^{1} \mathrm{H}\right\}$ NMR (101 MHz, DMSO- $d_{6}$ ) of compound $\mathbf{3 h}$ 


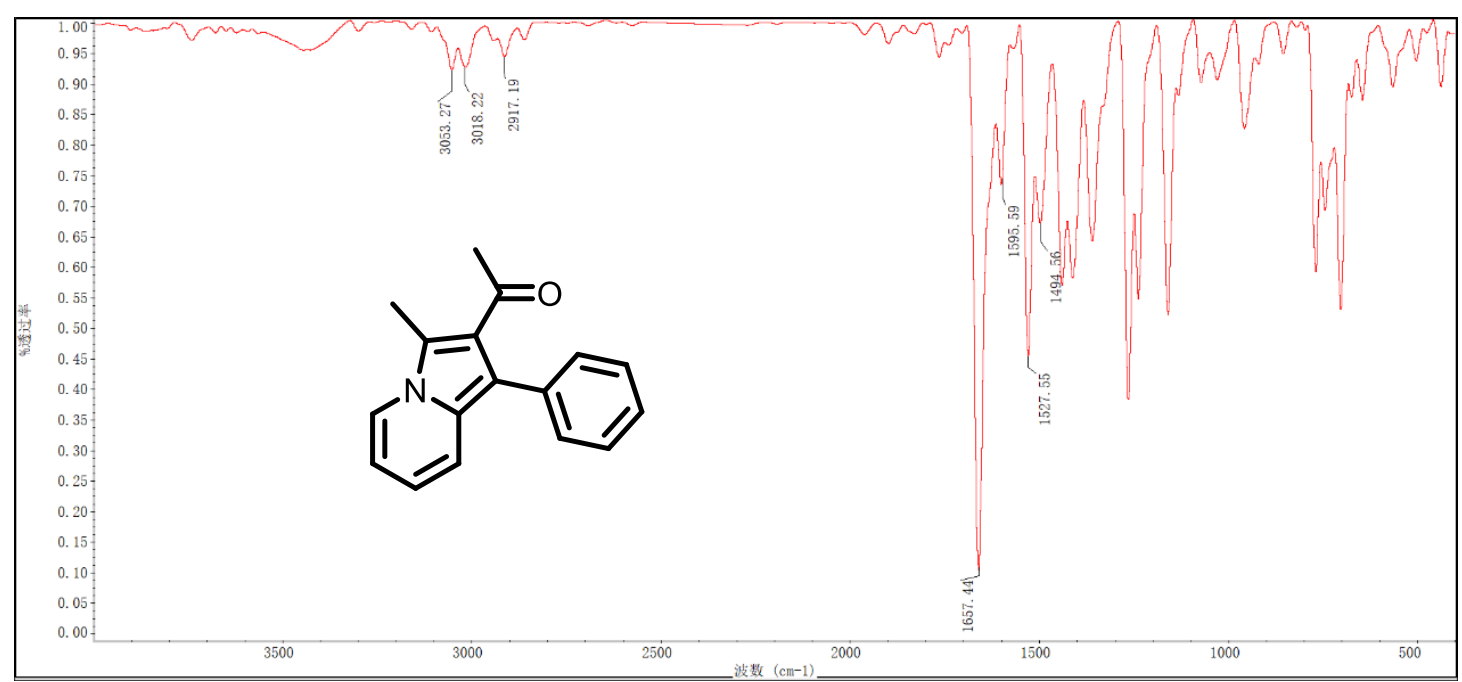

Figure S31 IR spectra of compound $\mathbf{3 h}$

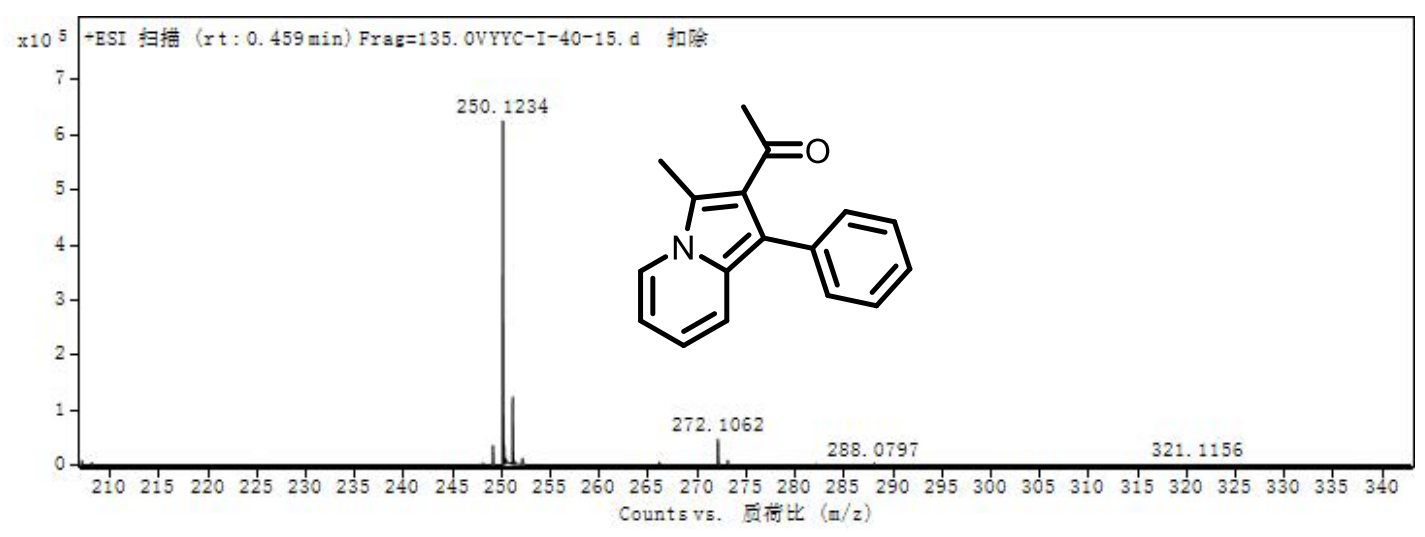

Figure S32 HRMS spectra of compound $\mathbf{3 h}$ 


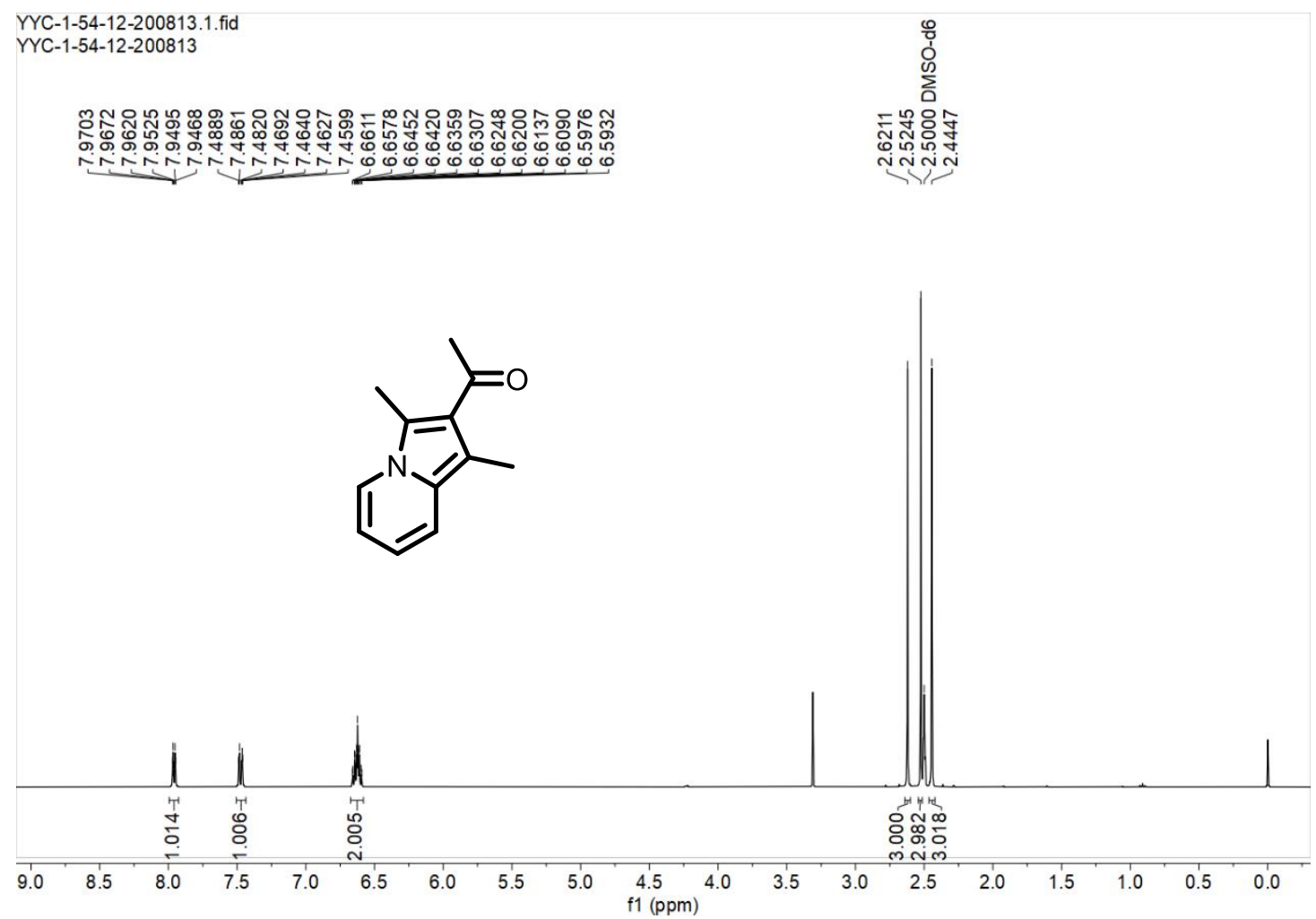

Figure S33 ${ }^{1} \mathrm{H}$ NMR (400 MHz, DMSO- $d_{6}$ ) of compound 3i

YYC-1-54-12-200821.1.fid YYC-1-54-14-200821

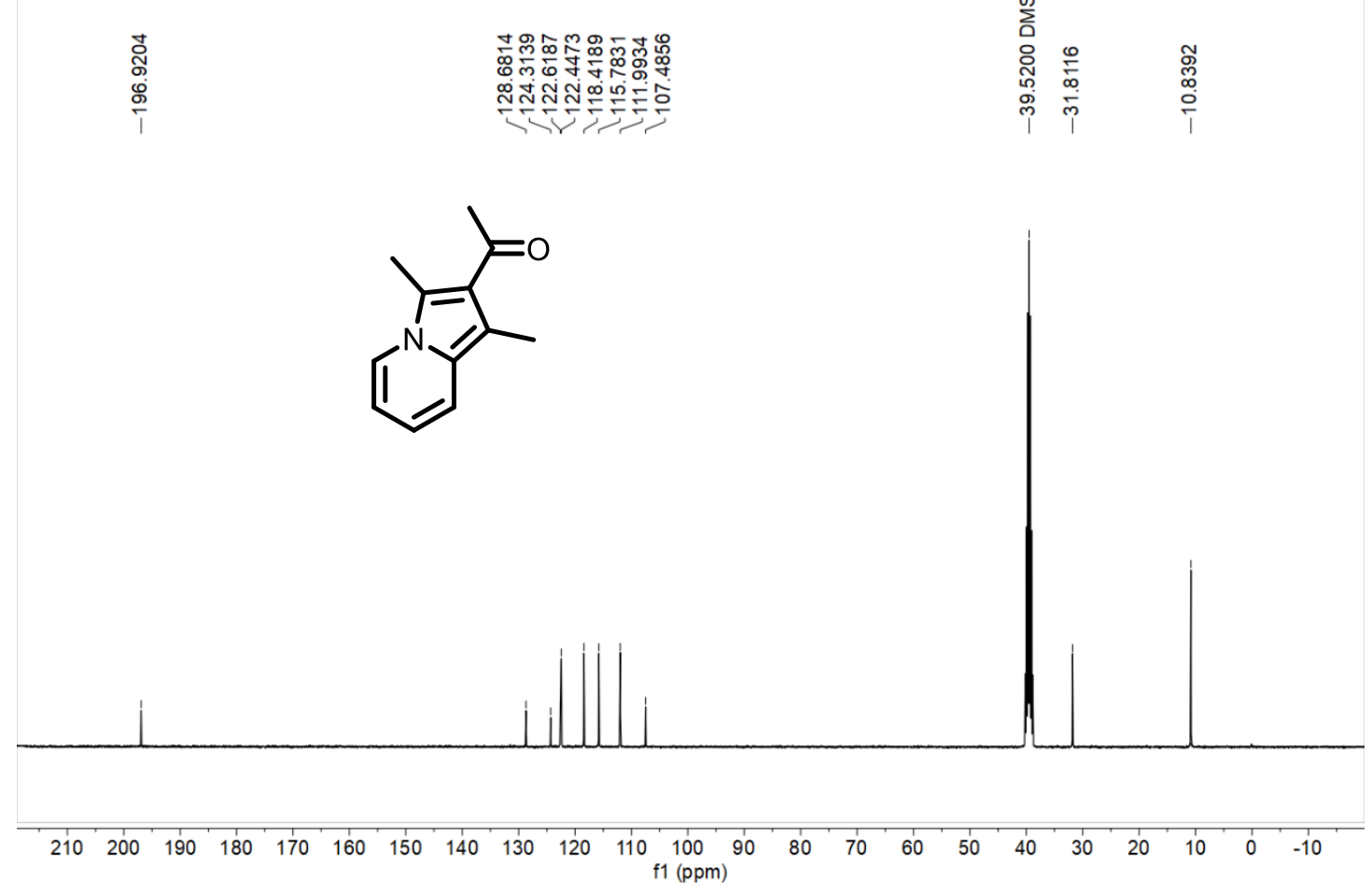

Figure $\mathrm{S} 34{ }^{13} \mathrm{C}\left\{{ }^{1} \mathrm{H}\right\}$ NMR (101 MHz, DMSO- $\left.d_{6}\right)$ of compound 3i 


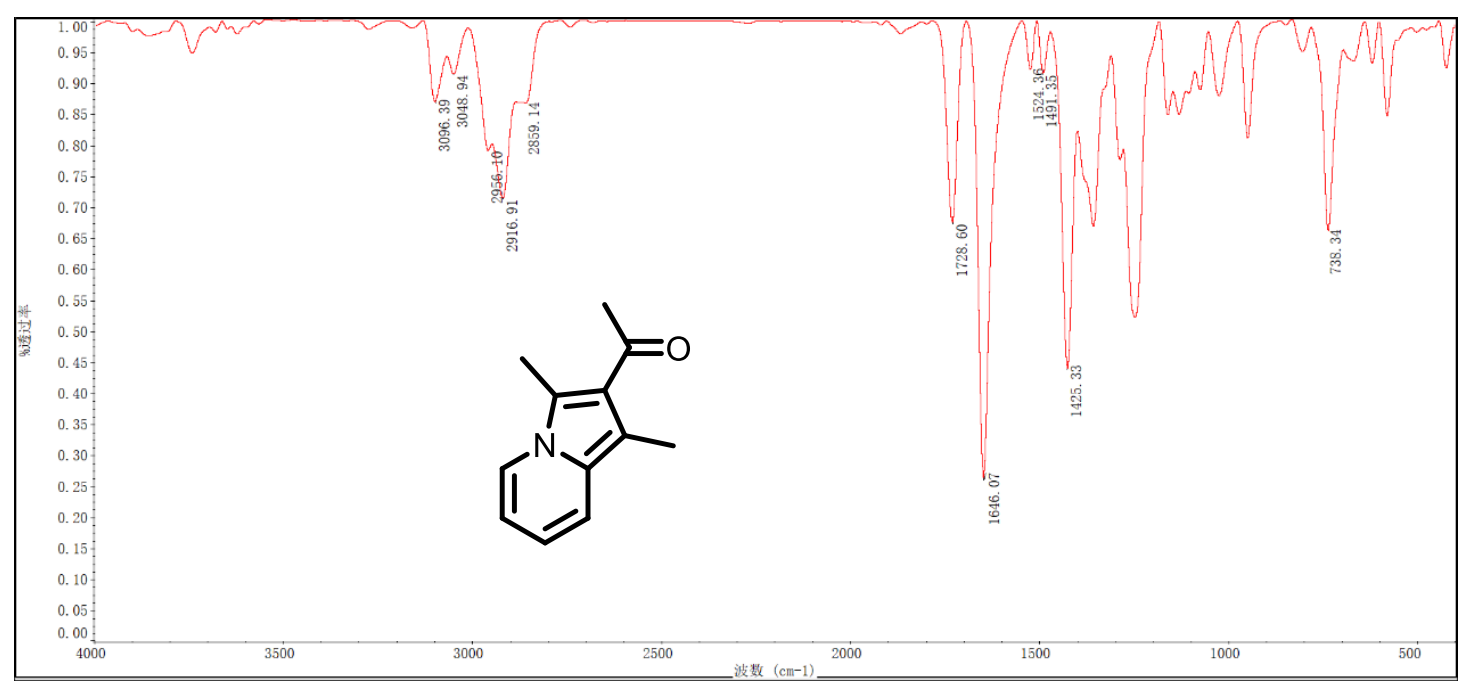

Figure S35 IR spectra of compound 3i

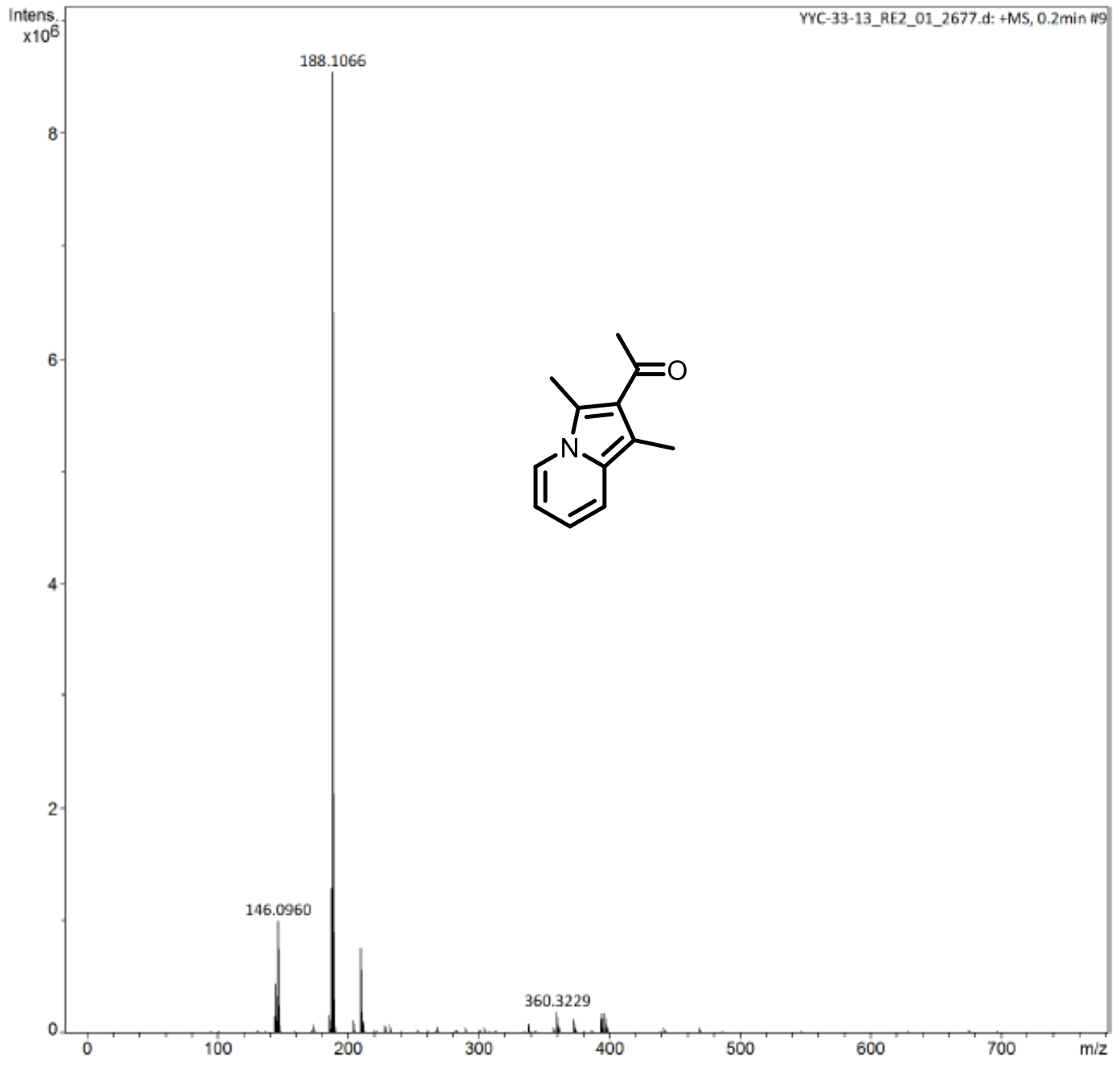

Figure S36 HRMS spectra of compound 3i 


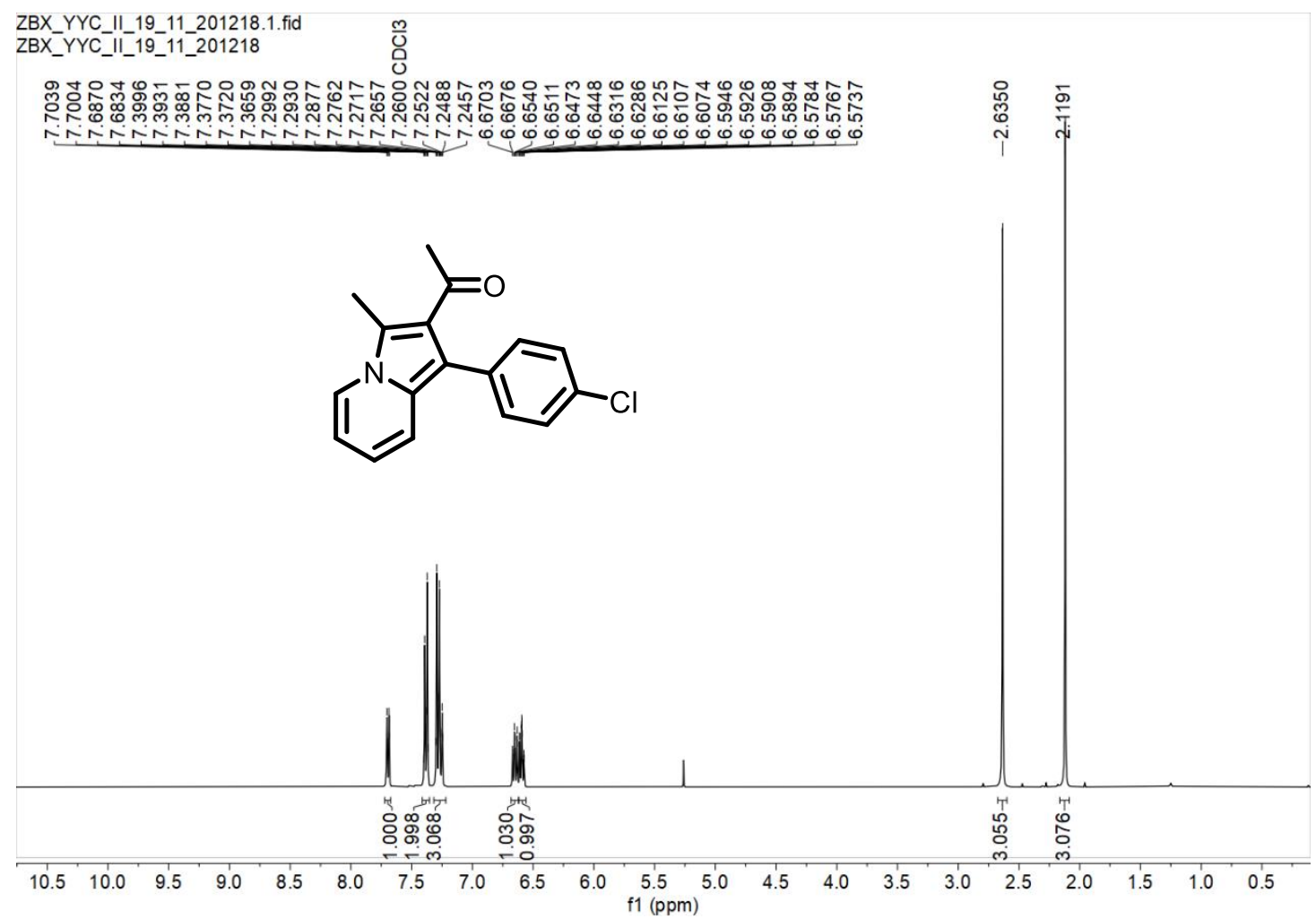

Figure S37 ${ }^{1} \mathrm{H}$ NMR (400 MHz, $\mathrm{CDCl}_{3}$ ) of compound $\mathbf{3 j}$

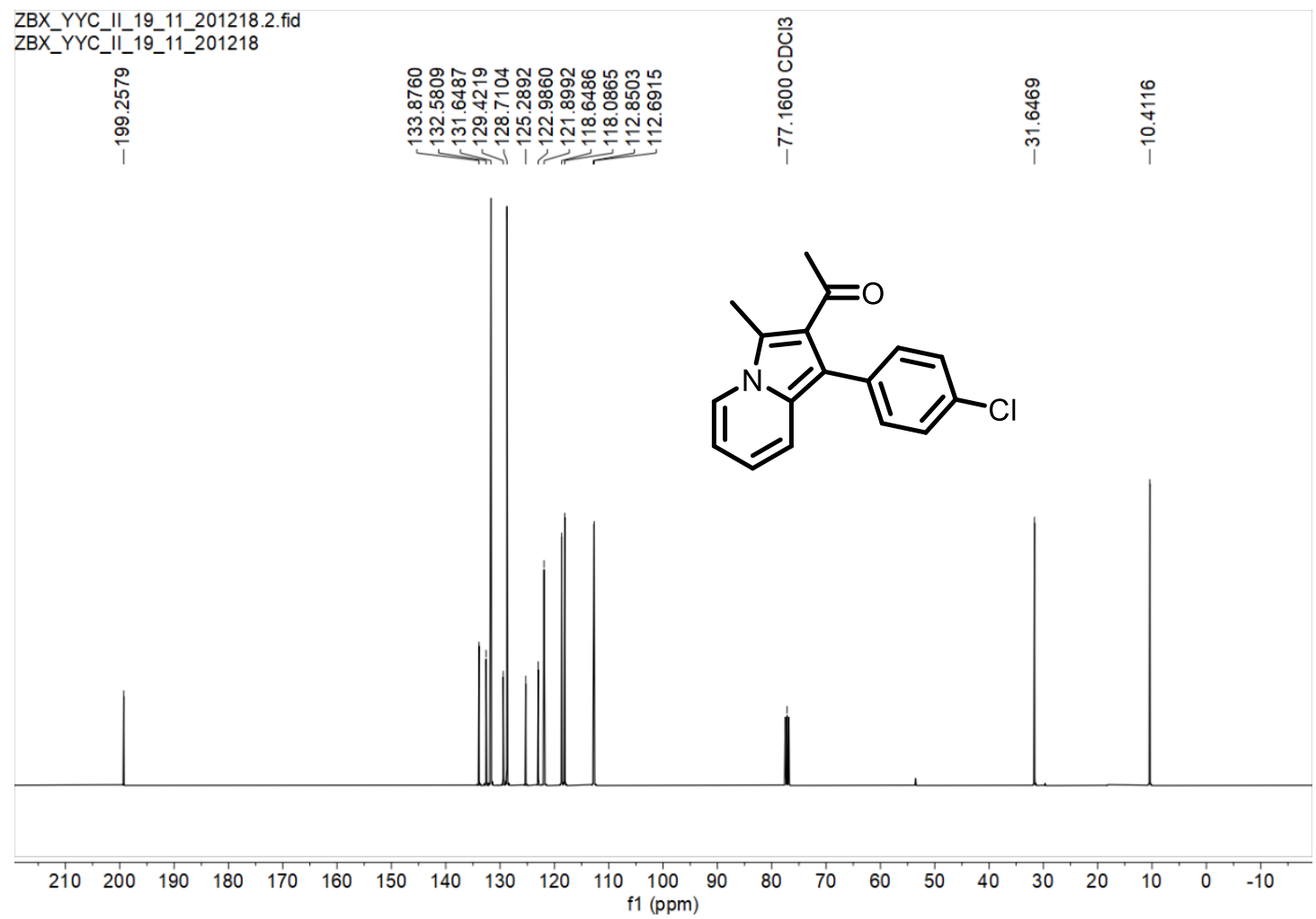

Figure $\mathrm{S} 38{ }^{13} \mathrm{C}\left\{{ }^{1} \mathrm{H}\right\} \mathrm{NMR}\left(101 \mathrm{MHz}, \mathrm{CDCl}_{3}\right)$ of compound $\mathbf{3 j}$ 


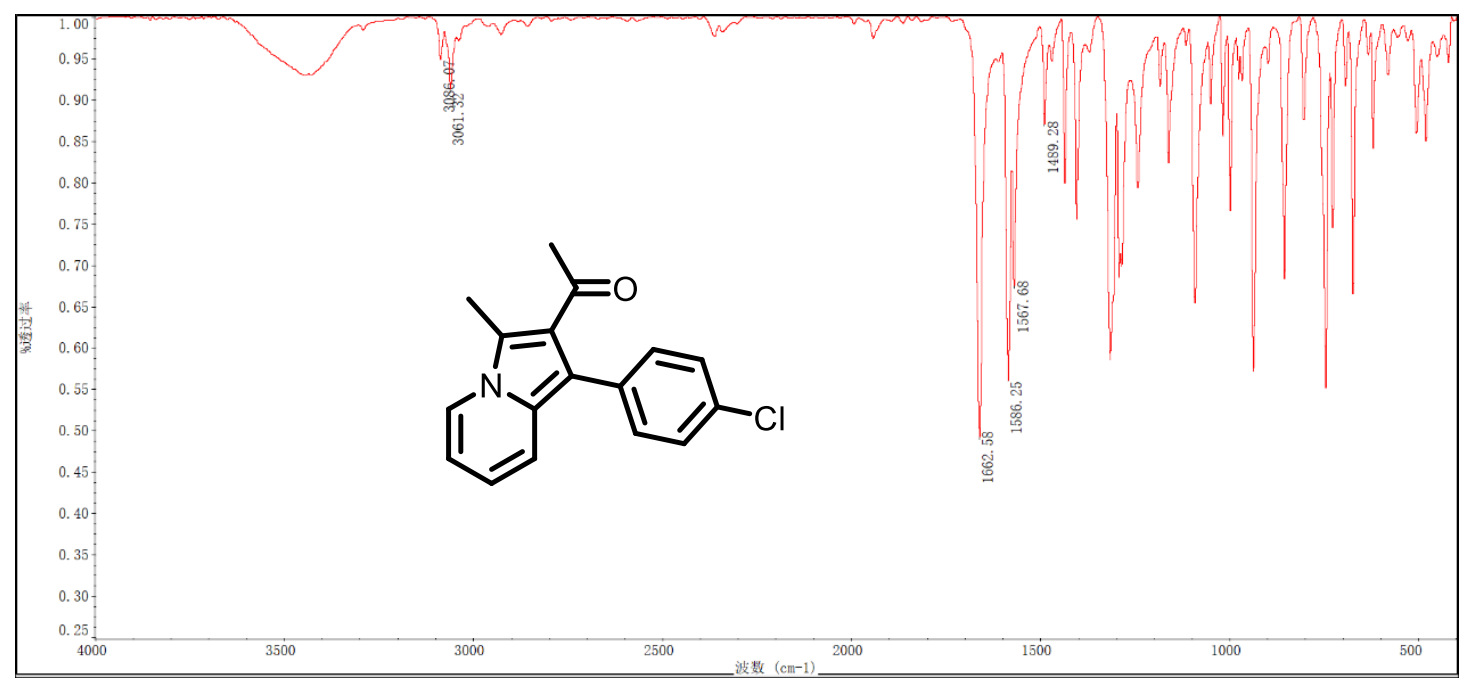

Figure S39 IR spectra of compound 3j

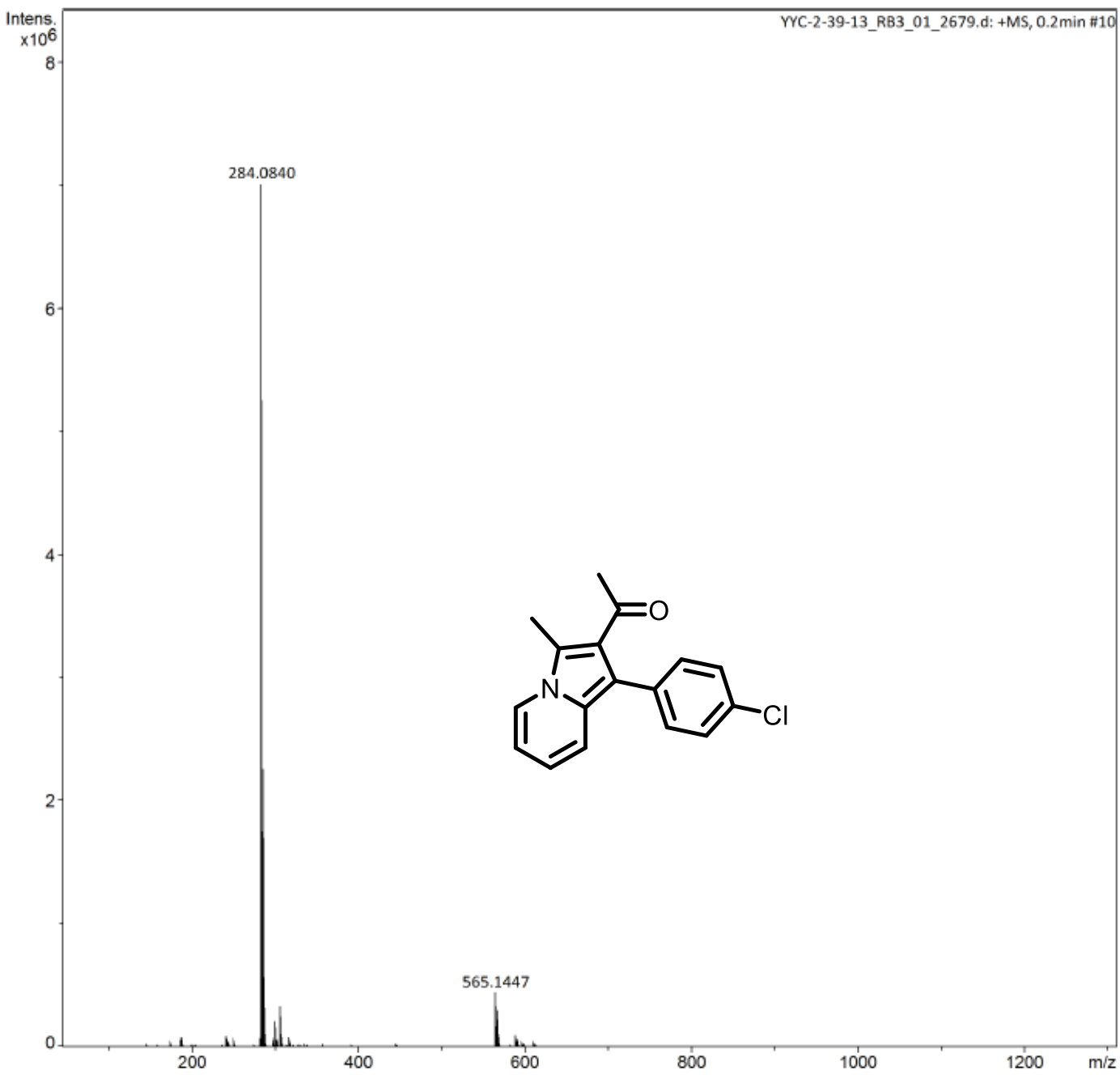

Figure S40 HRMS spectra of compound $\mathbf{3 j}$ 


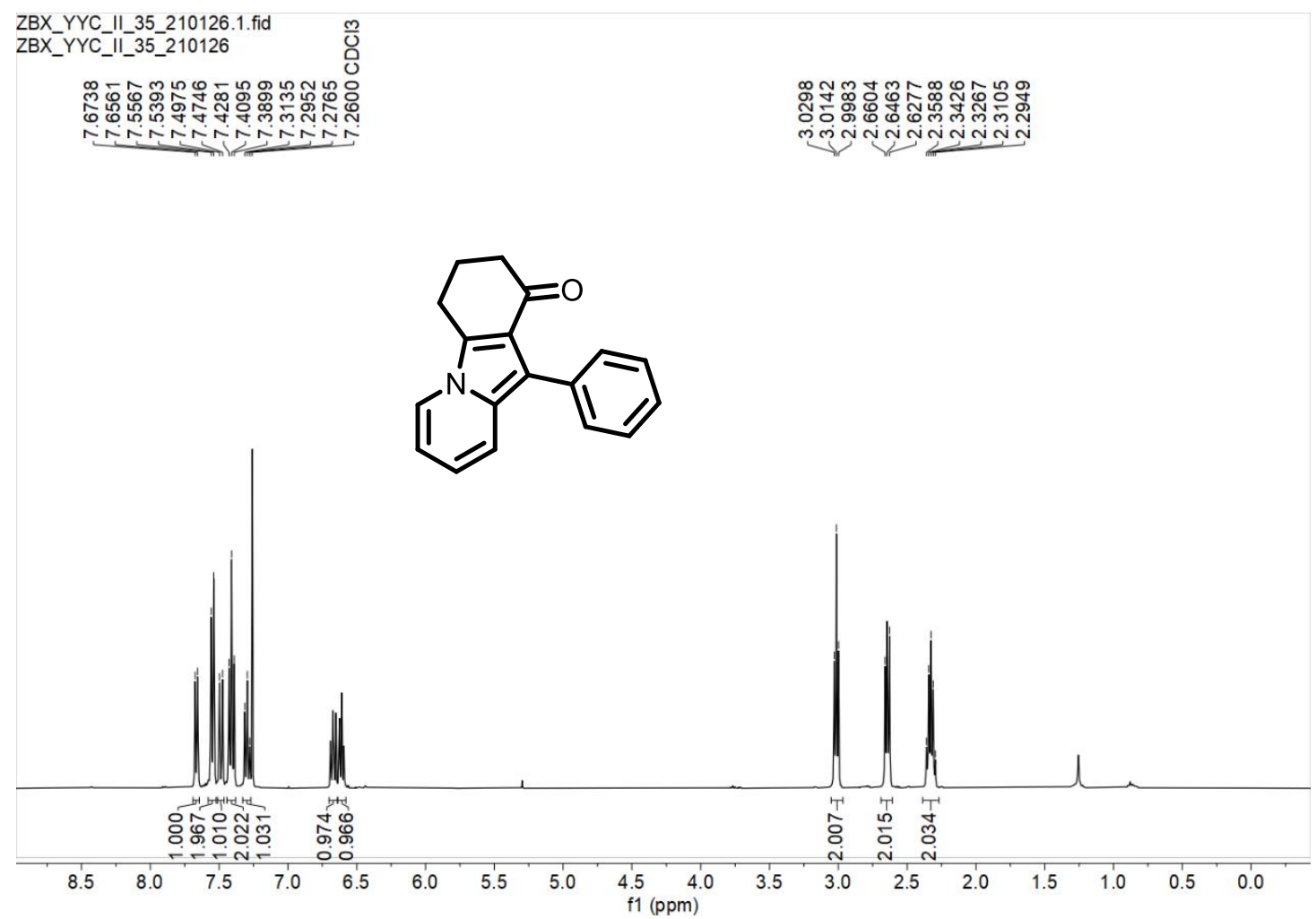

Figure $\mathrm{S} 41{ }^{1} \mathrm{H}$ NMR $\left(400 \mathrm{MHz}, \mathrm{CDCl}_{3}\right)$ of compound $\mathbf{3 k}$

ZBX_YYC_I666_14_2012013.1. fid ZBX_YYC_I66_14_2012013

$\frac{\substack{n \\ \frac{5}{5}}}{5}$

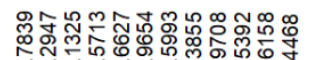

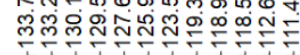

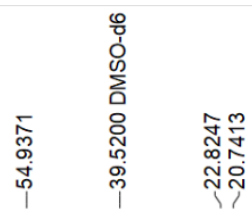

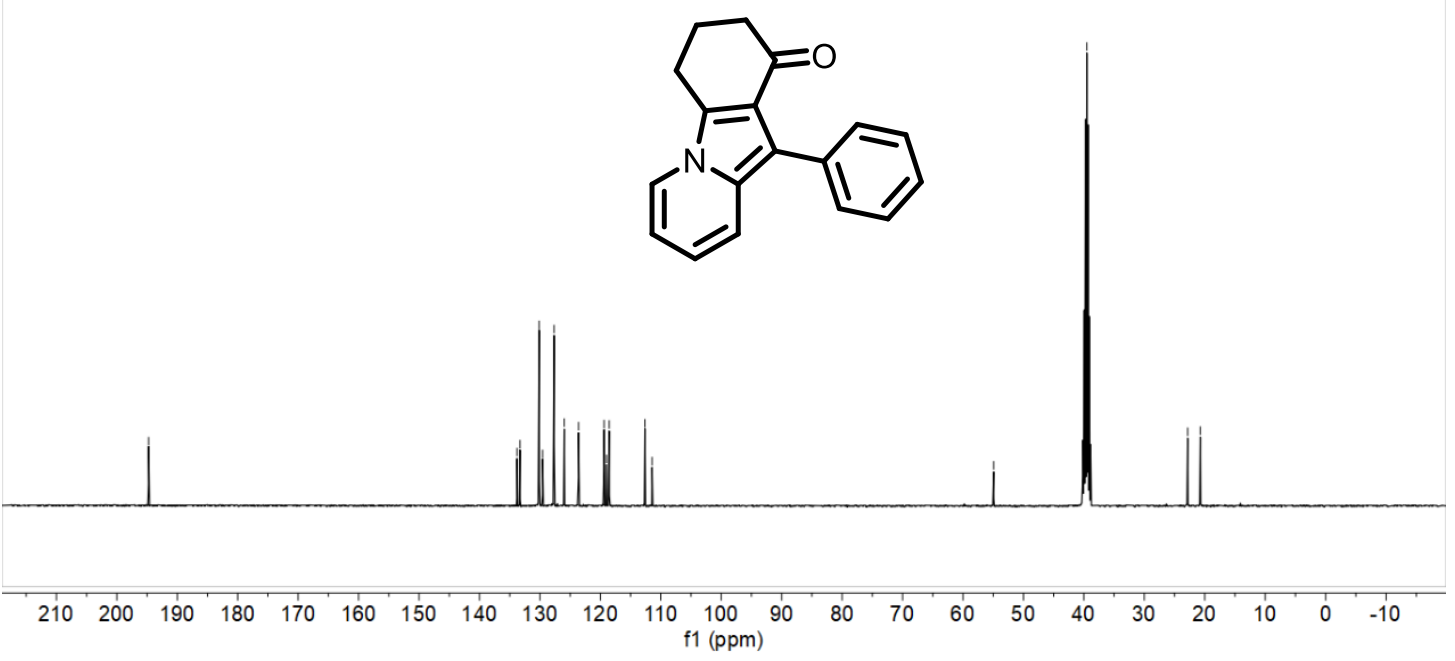

Figure S42 ${ }^{13} \mathrm{C}\left\{{ }^{1} \mathrm{H}\right\}$ NMR (101 MHz, DMSO- $\left.d_{6}\right)$ of compound 3k 


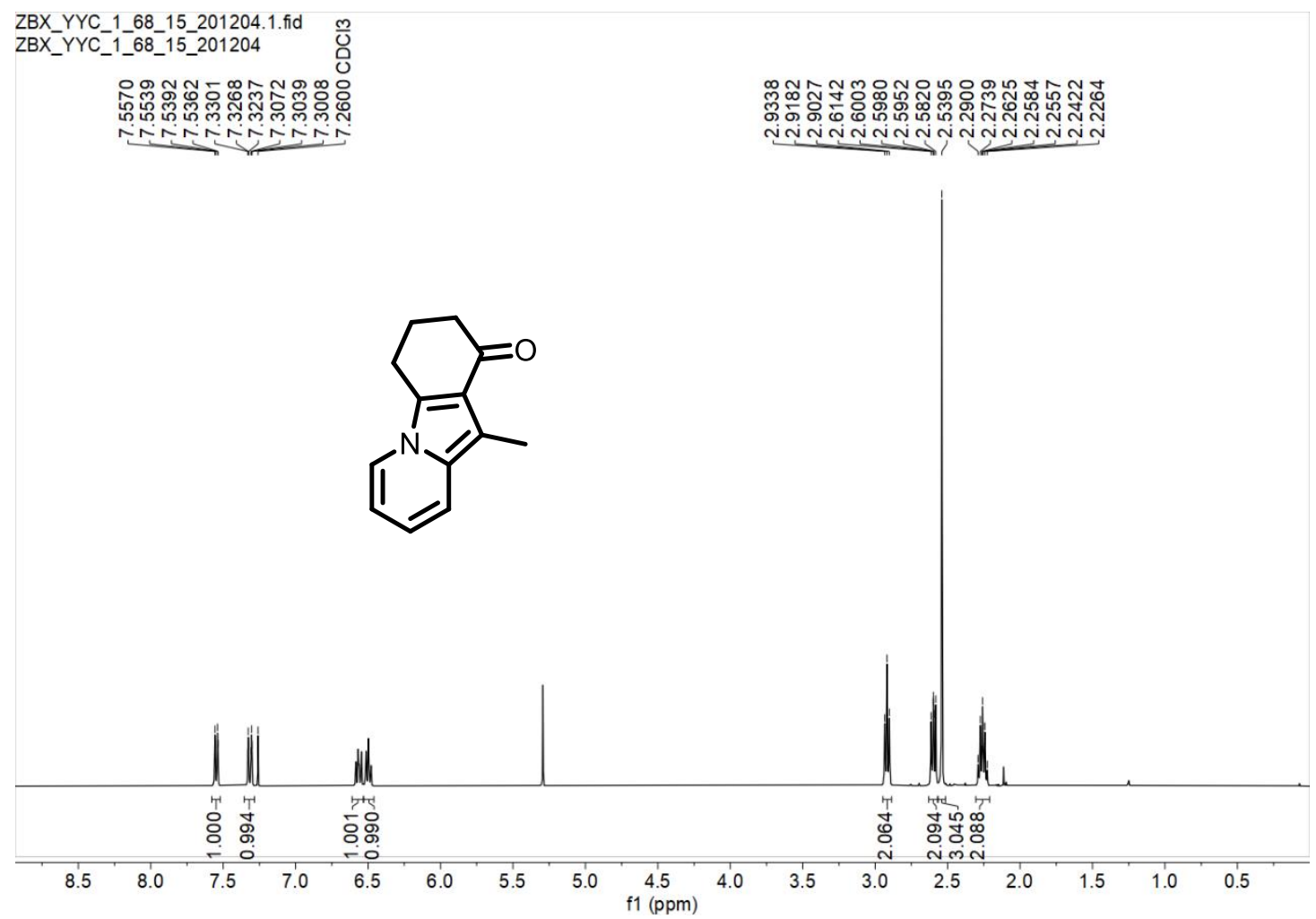

Figure $\mathrm{S} 43{ }^{1} \mathrm{H}$ NMR $\left(400 \mathrm{MHz}, \mathrm{CDCl}_{3}\right)$ of compound $3 \mathbf{I}$

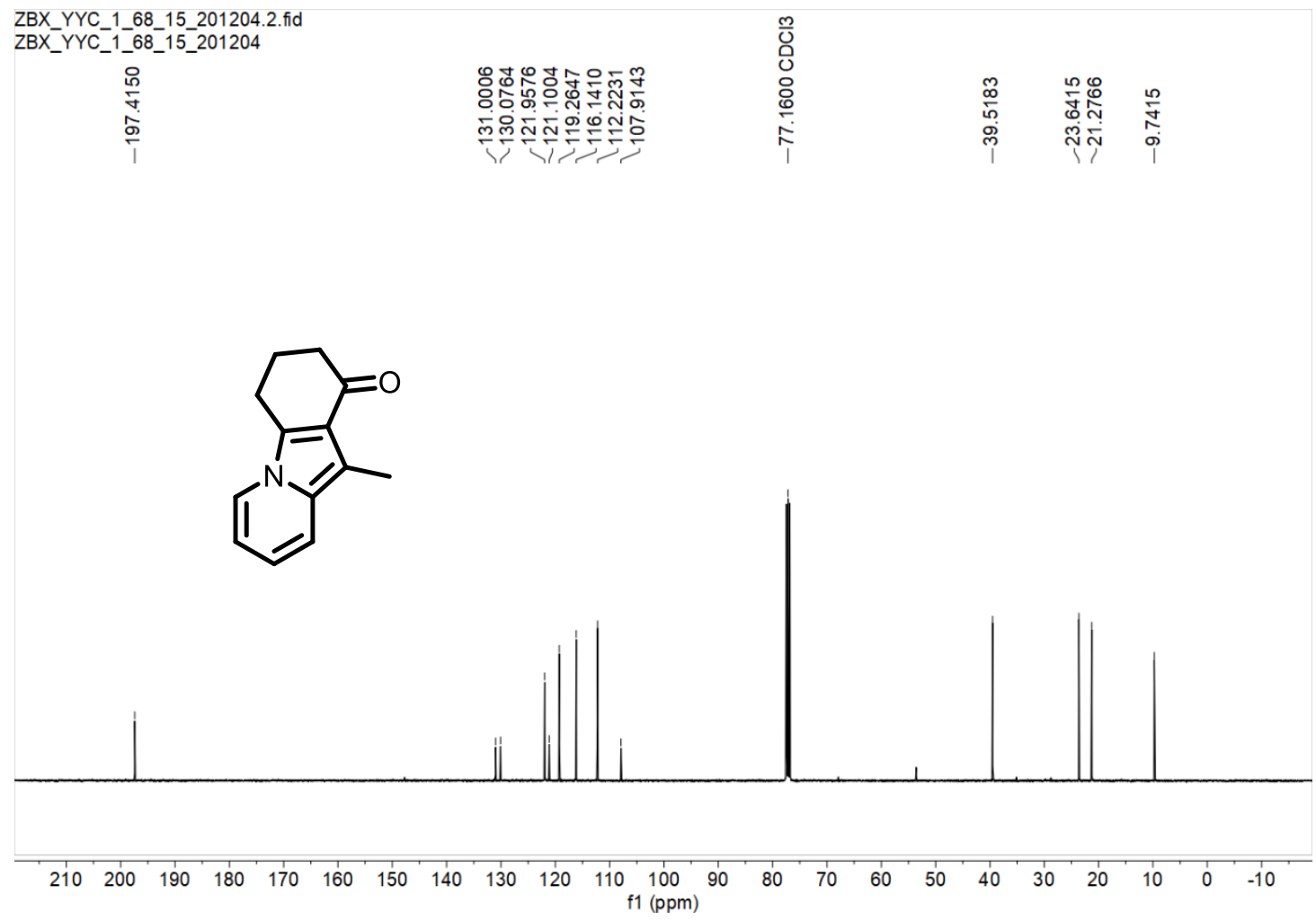

Figure $\mathrm{S} 44{ }^{13} \mathrm{C}\left\{{ }^{1} \mathrm{H}\right\}$ NMR (101 MHz, $\left.\mathrm{CDCl}_{3}\right)$ of compound $3 \mathrm{I}$ 


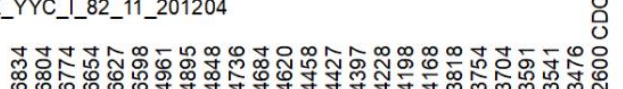

Ninn

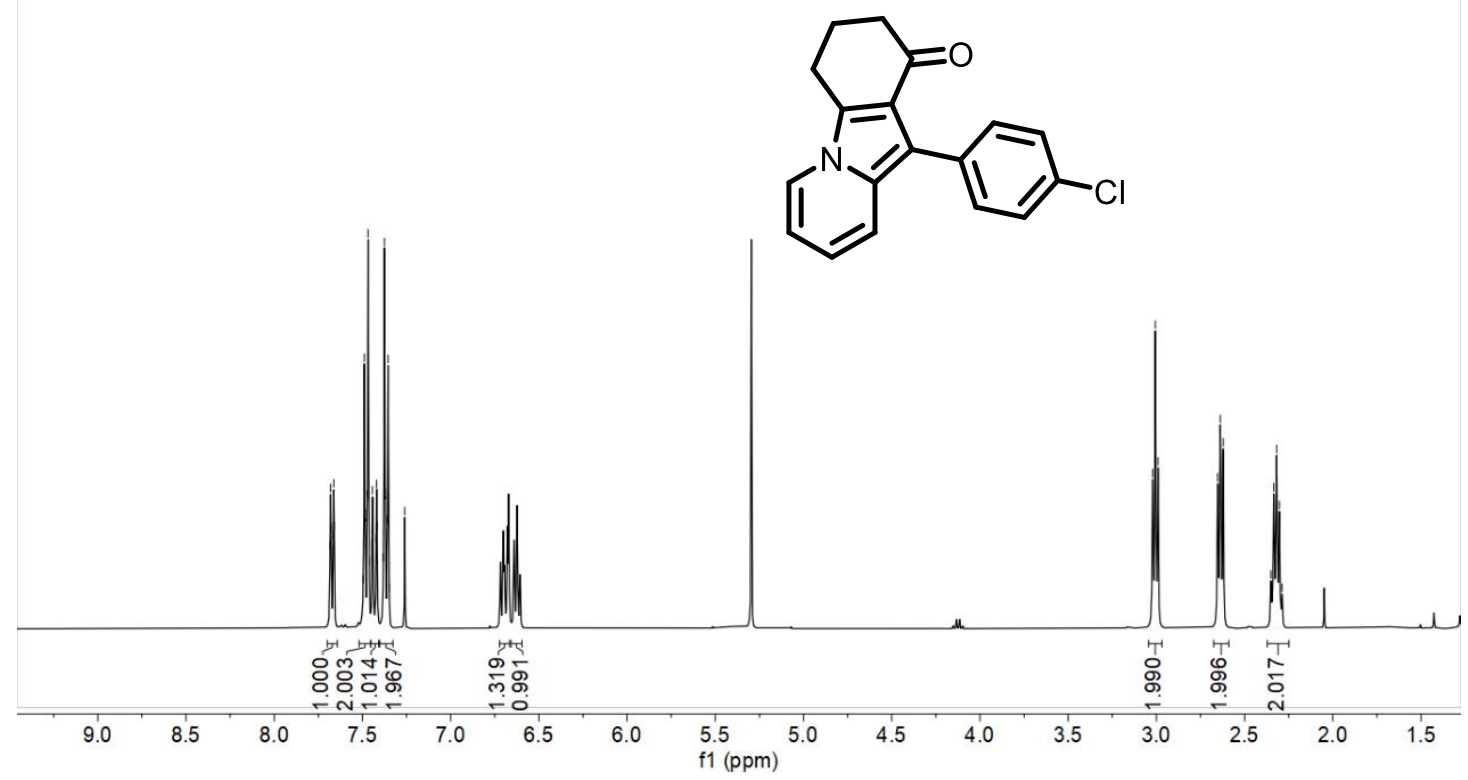

Figure $\mathrm{S} 45{ }^{1} \mathrm{H}$ NMR (400 MHz, $\mathrm{CDCl}_{3}$ ) of compound $\mathbf{3 m}$

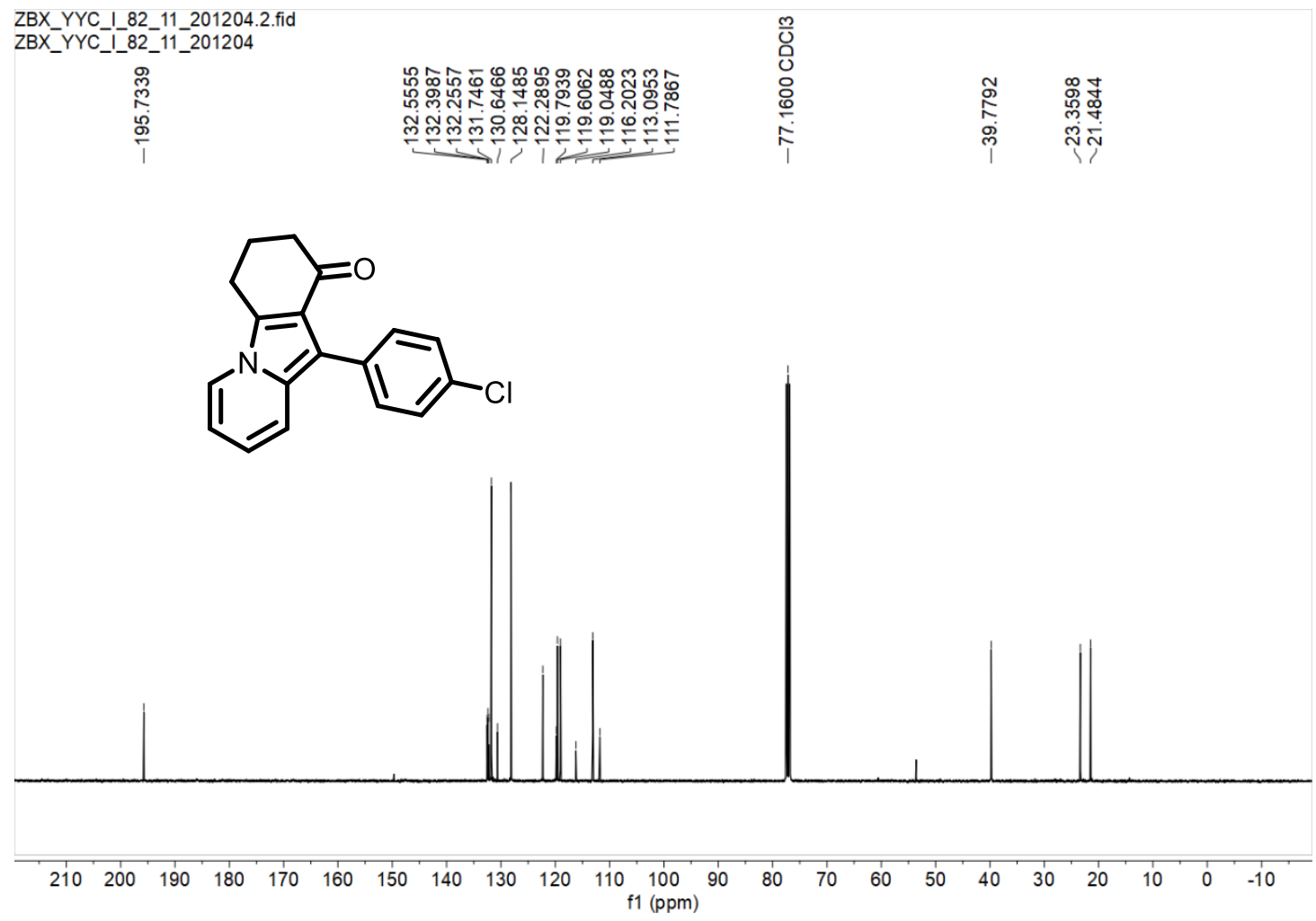

Figure $\mathrm{S} 46{ }^{13} \mathrm{C}\left\{{ }^{1} \mathrm{H}\right\} \mathrm{NMR}\left(101 \mathrm{MHz}, \mathrm{CDCl}_{3}\right)$ of compound $\mathbf{3 m}$ 


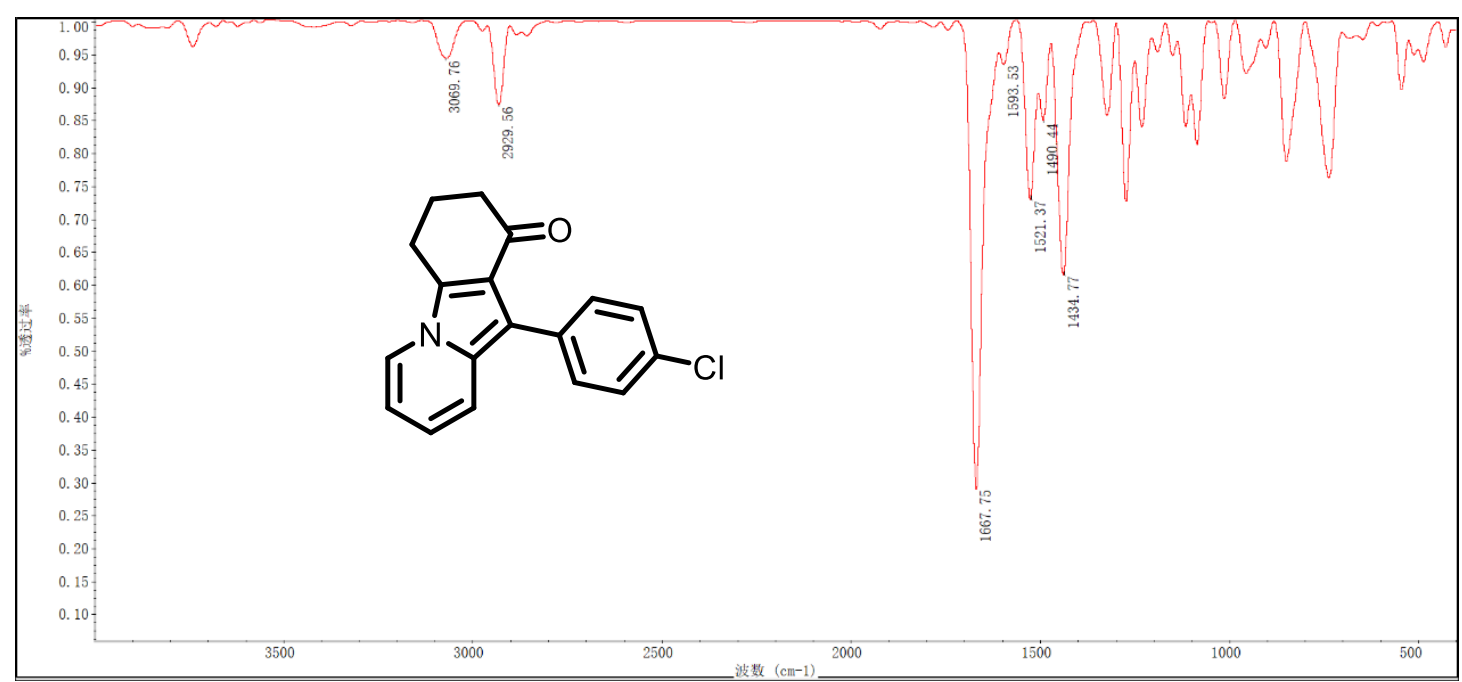

Figure S47 IR spectra of compound $\mathbf{3 m}$

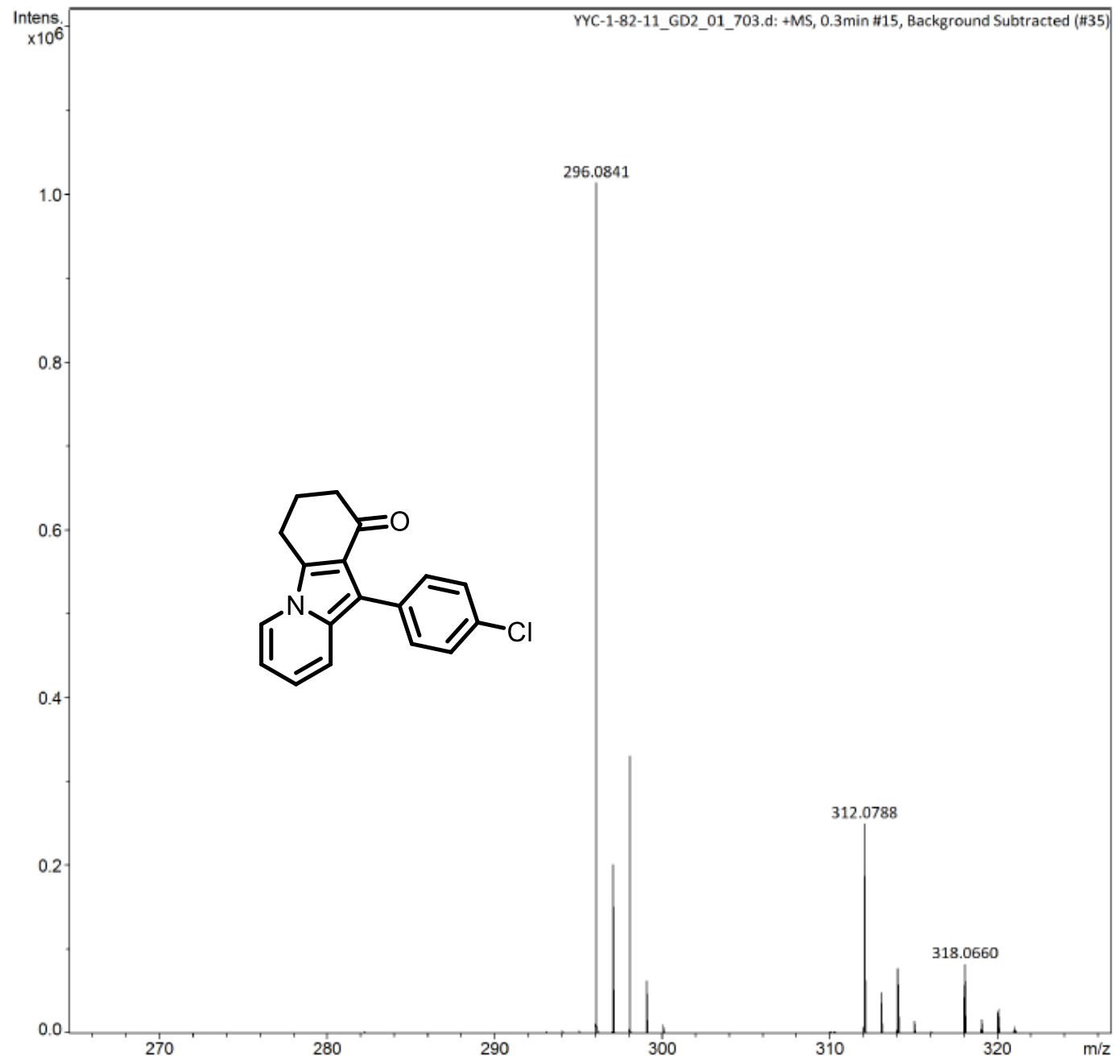

Figure S48 HRMS spectra of compound $\mathbf{3 m}$ 


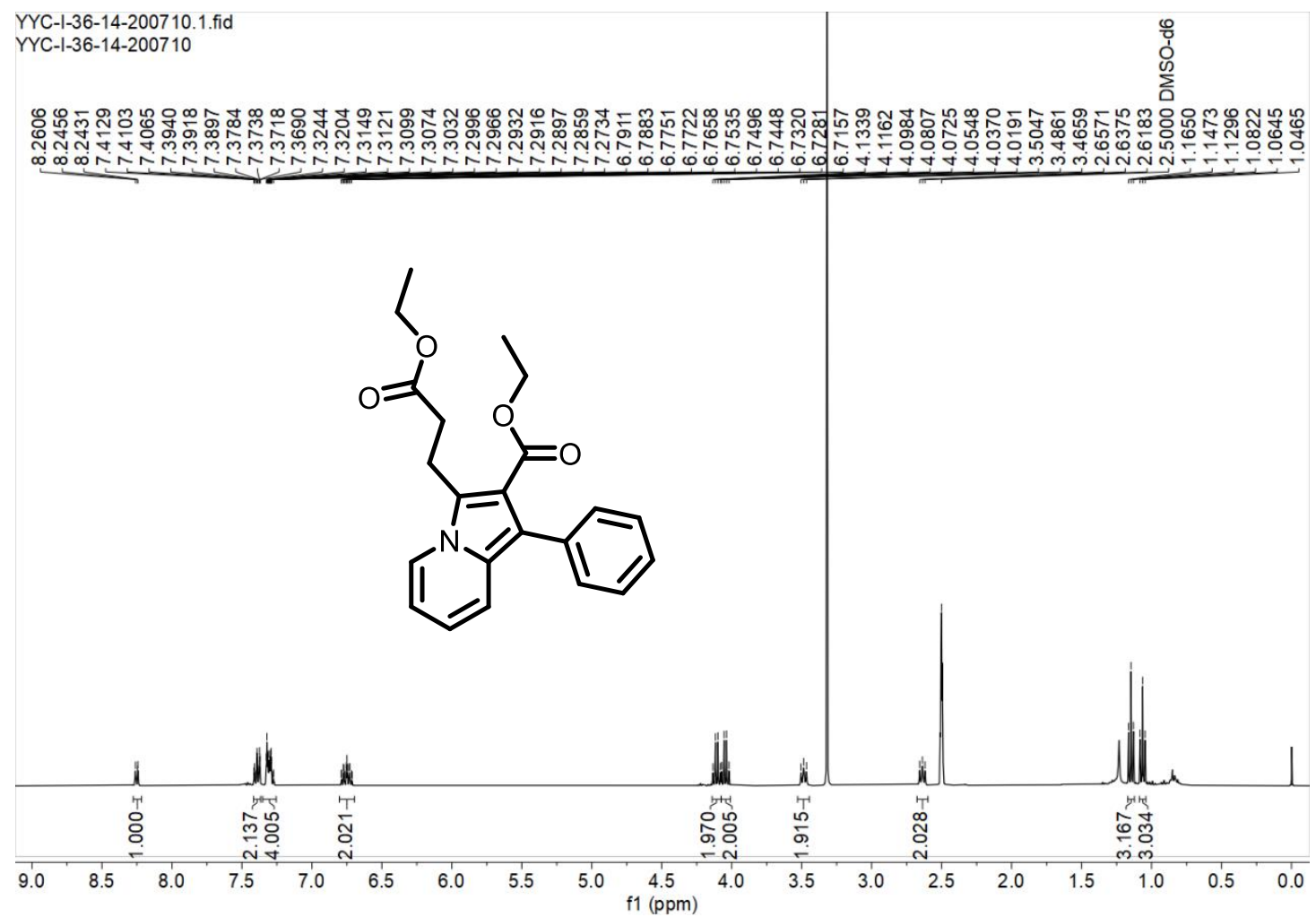

Figure S49 ${ }^{1} \mathrm{H}$ NMR (400 MHz, DMSO- $d_{6}$ ) of compound 3n

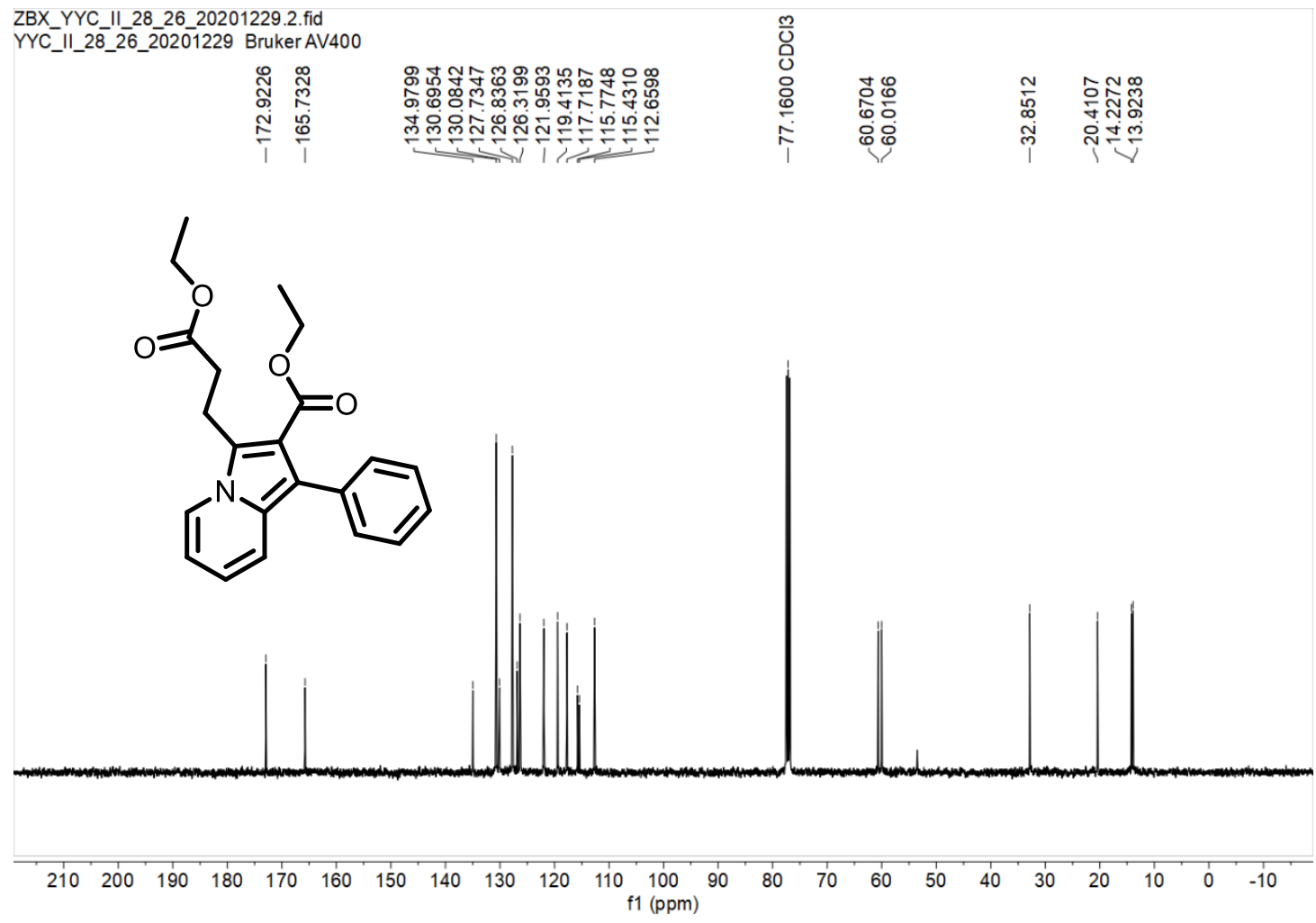

Figure $\mathrm{S} 50{ }^{13} \mathrm{C}\left\{{ }^{1} \mathrm{H}\right\}$ NMR (101 MHz, $\left.\mathrm{CDCl}_{3}\right)$ of compound 3n 


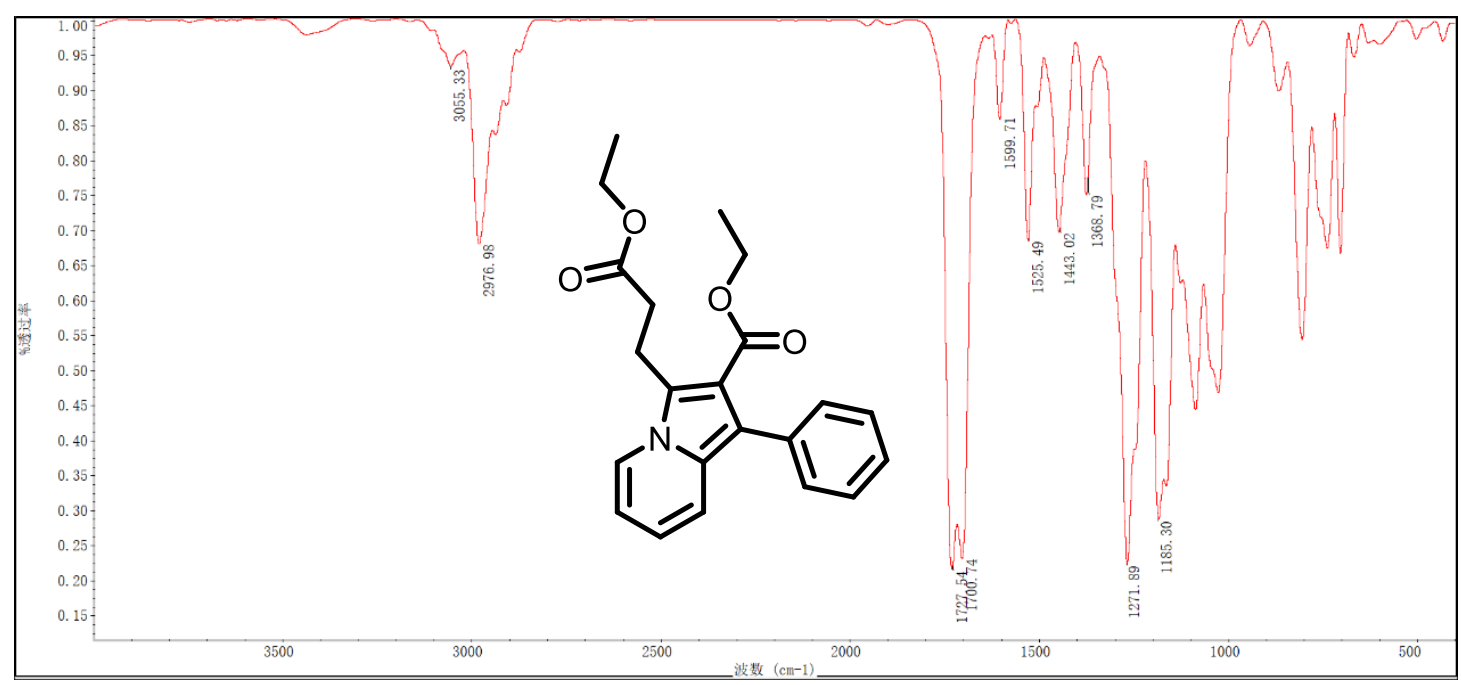

Figure S51 IR spectra of compound 3n

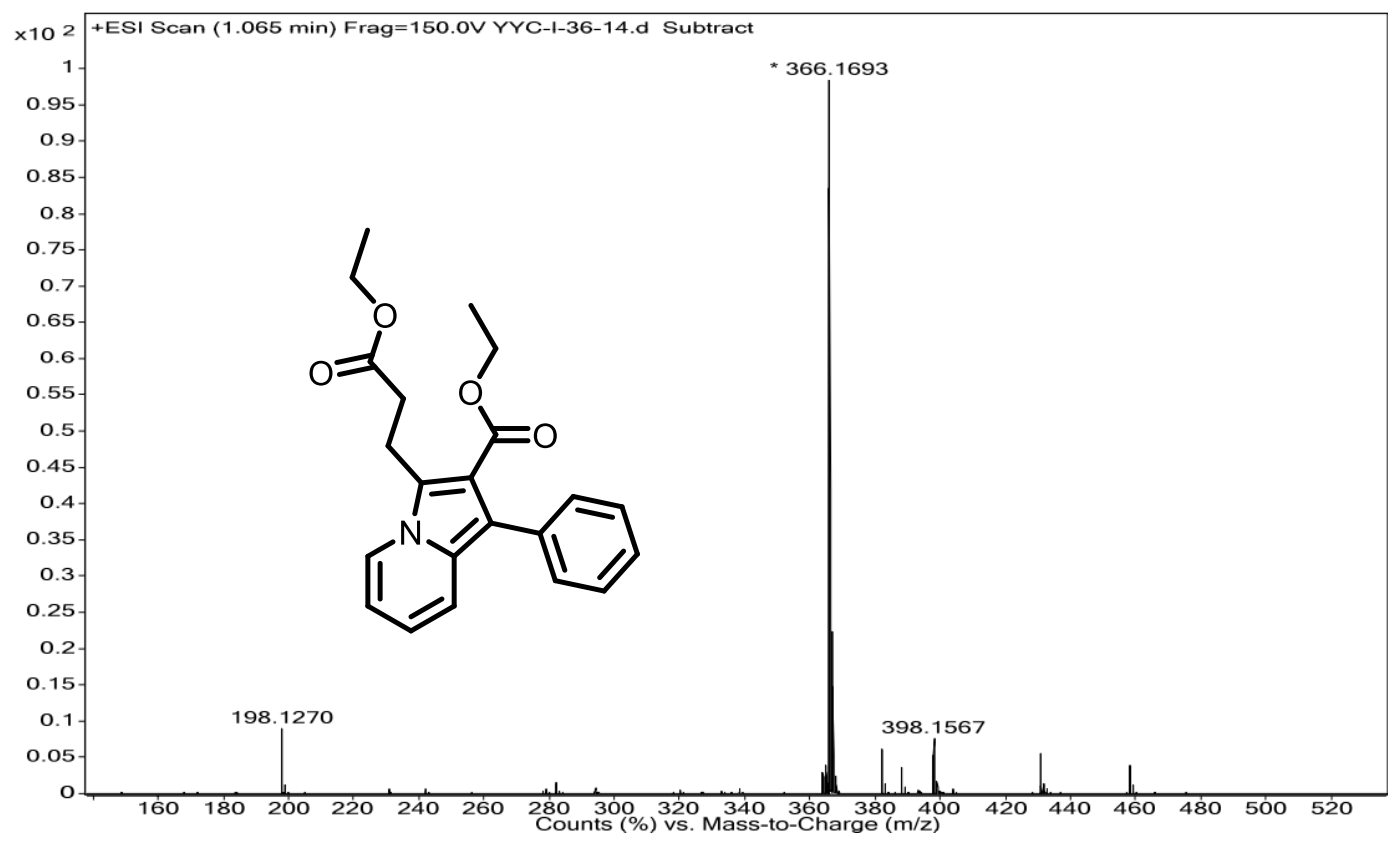

Figure S52 HRMS spectra of compound $\mathbf{3 n}$ 


\section{UV-Vis spectroscopy}

(a)

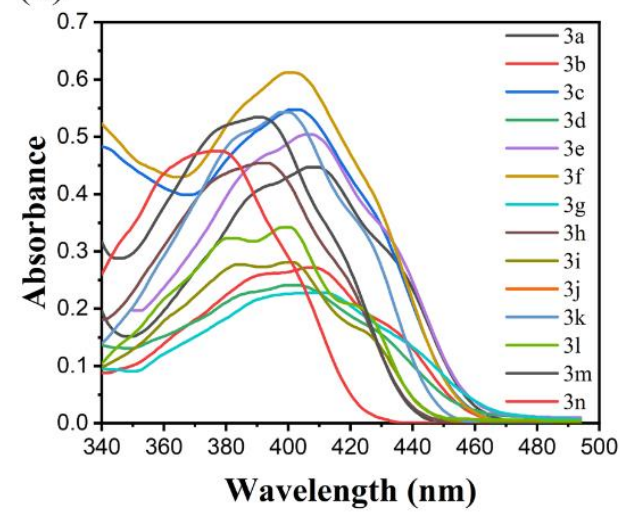

(b)

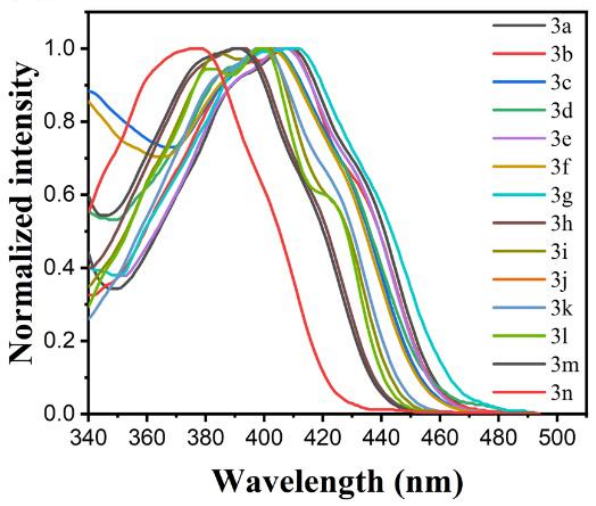

Figure S53 UV-vis absorption spectra and normalized spectra of compounds 3a-3n in dimethyl sulfoxide $\left(1.2 \times 10^{-4} \mathrm{M}\right)$.

(a)

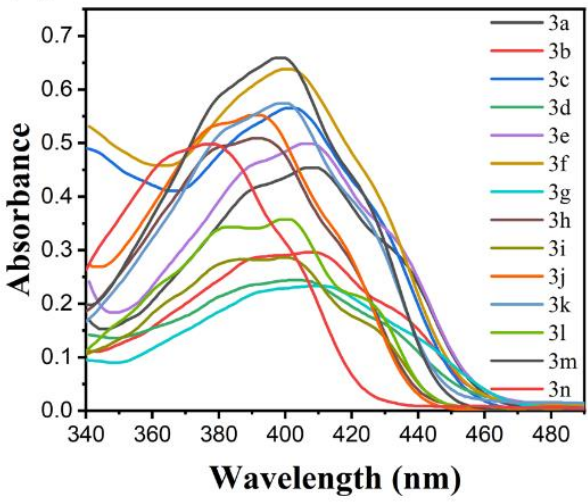

(b)

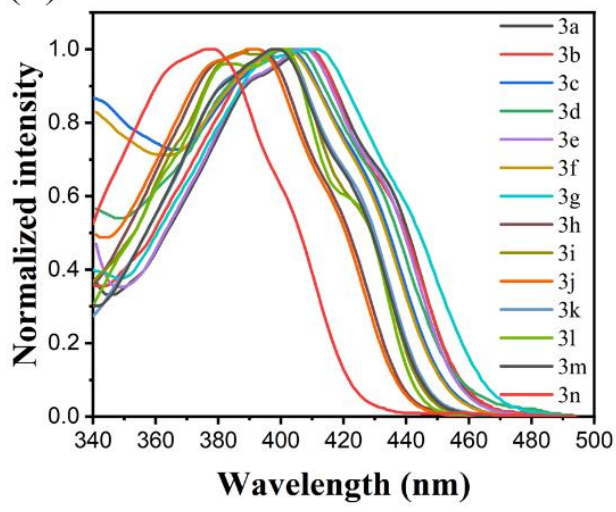

Figure S54 UV-vis absorption spectra and normalized spectra of compounds $\mathbf{3 a - 3 n}$ in dichloromethane

$$
\left(1.2 \times 10^{-4} \mathrm{M}\right) .
$$

(a)

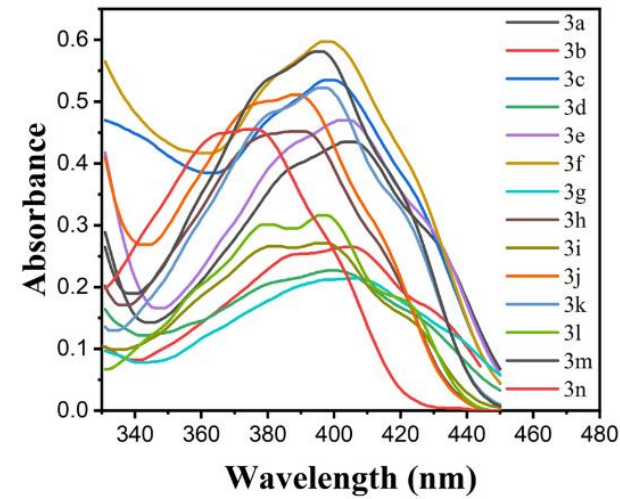

(b)

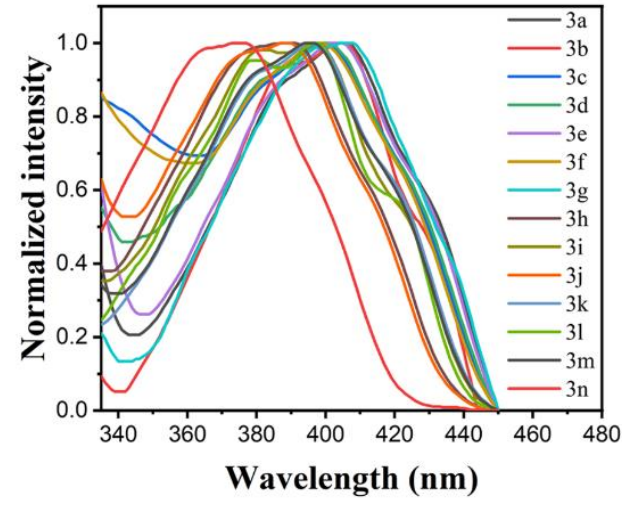

Figure S55 UV-vis absorption spectra and normalized spectra of compounds $\mathbf{3 a - 3 n}$ in acetonitrile $\left(1.2 \times 10^{-4} \mathrm{M}\right)$ 


\section{Fluorescence spectra}

(a)

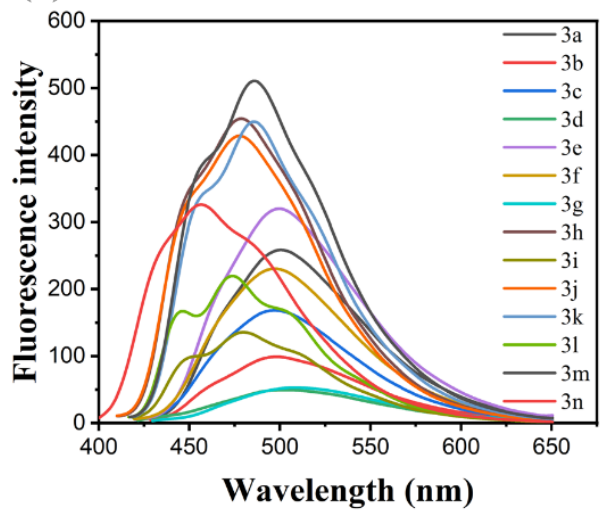

(b)

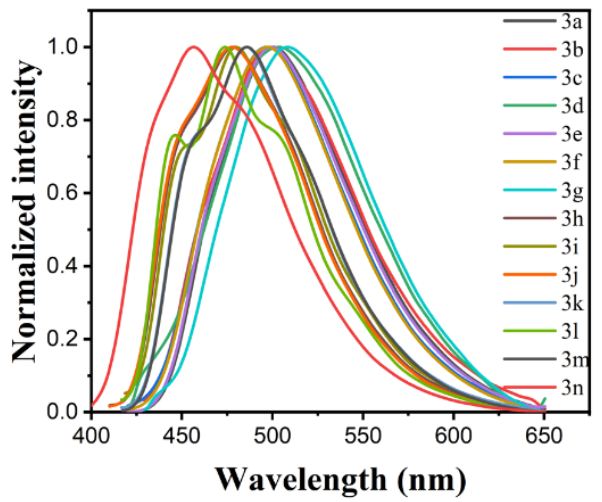

Figure S56 Fluorescence spectra and normalized fluorescence spectra of the compounds $\mathbf{3 a - 3 n}$ in dichloromethane $\left(5 \times 10^{-6} \mathrm{M}\right)$.

(a)

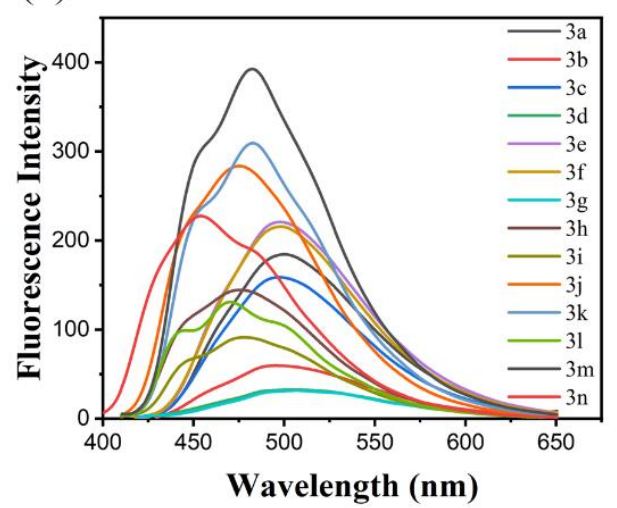

(b)

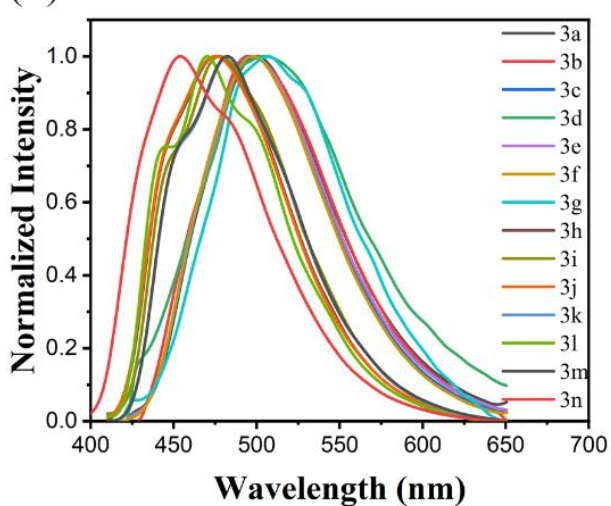

Figure S57 Fluorescence spectra and normalized fluorescence spectra of the compounds $\mathbf{3 a - 3 n}$ in acetonitrile $\left(5 \times 10^{-6} \mathrm{M}\right)$. 


\section{X-Ray diffraction analyses}

10-(4-chlorophenyl)-3,4-dihydropyrido[1,2-a]indol-1(2H)-one (3m, CCDC: 2085860).

$\mathrm{X}$-Ray structures are depicted as thermal ellipsoids at a $50 \%$ probability level using the following colour code: $\mathrm{C}$, grey; $\mathrm{H}$, white; $\mathrm{Cl}$, light green; $\mathrm{N}$, blue; $\mathrm{O}$, red.
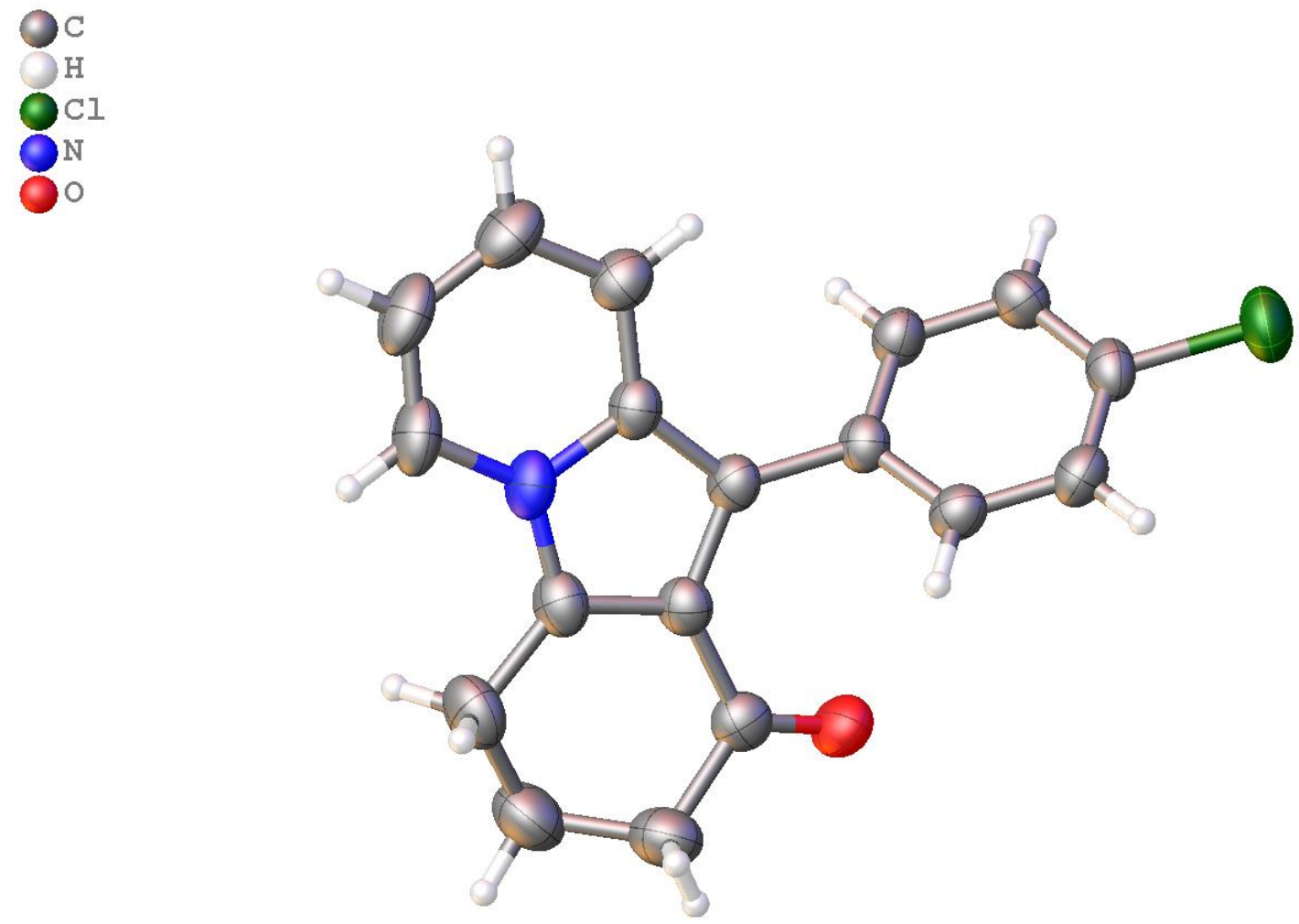

Table S1. Summary of crystallographic data and structure refinement parameters for $\mathbf{3 m}$.

\begin{tabular}{ll} 
Compound & $3 \mathrm{~m}$ \\
Empirical formula & $\mathrm{C}_{18} \mathrm{H}_{14} \mathrm{ClNO}$ \\
Formula weight & 295.75 \\
Temperature/K & $293(2)$ \\
Crystal system & monoclinic \\
Space group & $\mathrm{P} 2_{1}$ \\
$\mathrm{a} / \AA$ & $8.9966(3)$ \\
$\mathrm{b} / \AA$ & $9.1093(2)$ \\
$\mathrm{c} / \AA$ & $9.1777(2)$ \\
$\alpha /{ }^{\circ}$ & 90 \\
$\beta /{ }^{\circ}$ & $109.020(3)$ \\
$\gamma /{ }^{\circ}$ & 90 \\
$\mathrm{Volume} / \AA^{3}$ & $711.07(3)$ \\
$\mathrm{Z}$ & 2 \\
$\rho_{\text {calcg }} / \mathrm{cm}^{3}$ & 1.381 \\
$\mu / \mathrm{mm}^{-1}$ & 2.347 \\
$\mathrm{~F}(000)$ & 308.0 \\
$\mathrm{Crystal} \mathrm{size} / \mathrm{mm}^{3}$ & $0.03 \times 0.02 \times 0.02$ \\
& \multicolumn{2}{c}{$\mathrm{S} 30$}
\end{tabular}


Radiation

$\mathrm{CuK} \alpha(\lambda=1.54184)$

$2 \Theta$ range for data collection $/{ }^{\circ} 10.194$ to 134.122

Index ranges

$-10 \leq \mathrm{h} \leq 10,-10 \leq \mathrm{k} \leq 10,-10 \leq 1 \leq 10$

Reflections collected 8194

Independent reflections

$2488\left[\mathrm{R}_{\text {int }}=0.0464, \mathrm{R}_{\text {sigma }}=0.0392\right]$

Data/restraints/parameters

$2488 / 1 / 191$

Goodness-of-fit on $\mathrm{F}^{2}$

1.037

Final $R$ indexes $[\mathrm{I}>=2 \sigma(\mathrm{I})] \quad \mathrm{R}_{1}=0.0331, \mathrm{wR}_{2}=0.0866$

Final $\mathrm{R}$ indexes [all data] $\quad \mathrm{R}_{1}=0.0342, \mathrm{wR}_{2}=0.0877$

Largest diff. peak/hole / e $\AA^{-3} 0.18 /-0.15$

Flack parameter

$-0.002(10)$ 